\title{
Functionality of amidines and amidrazones
}

\author{
Ashraf A. Aly* and Ahmed M. Nour-El-Din \\ Chemistry Department, Faculty of Science, El-Minia University \\ 61519-El-Minia, A. R. Egypt \\ E-mail: ashrafaly63@yahoo.com
}

\begin{abstract}
The review summarizes literature dealing with the synthesis of amidines and amidrazones including some of their physical and chemical properties along with their applications in heterocycles synthesis.
\end{abstract}

Keywords: Amidines, amidrazones, heterocycles

\section{Contents}

Introduction

1. Synthesis of Amidines

2. Cyclic Amidines

3. Miscellaneous Amidines

4. Amidines as Building Blocks in Synthesis

4.1. Synthesis of amidrazones and amidoximes

4.2. Synthesis of heterocyclic derivatives

5. Amidrazones

5.1. General properties

5.2. Methods in the synthesis of amidrazones

5.3. Reactions of amidrazones

6. Reaction of Monosaccharides with 2-Pyridylcarboxamidrazone

7. Industrial and Medicinal Applications of Amidrazones

References 


\section{Introduction}

The amidino group in 1a, which contains an amino nitrogen atom with a free electron pair conjugated with the $\pi$-electrons of the $\mathrm{C}=\mathrm{N}$ double bond, is the bis-nitrogen analogue of carboxylic acids and esters $2 .{ }^{1}$ It combines the properties of an azomethine-like $\mathrm{C}=\mathrm{N}$ double bond with an amide like $\mathrm{C}-\mathrm{N}$ single bond with a partial double bond character as indicated by the resonance form $\mathbf{1} \mathbf{b} .^{2,3}$

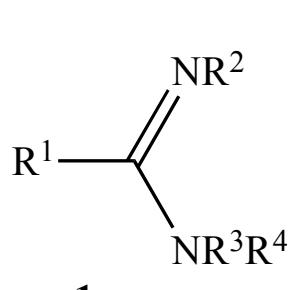

$1 \mathbf{a}$

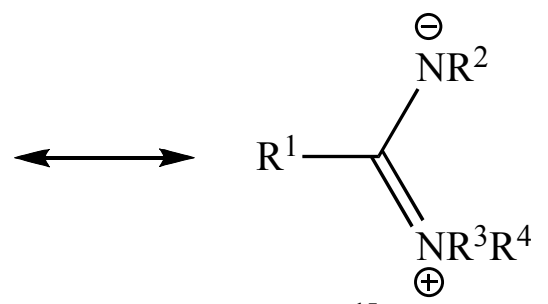

1b

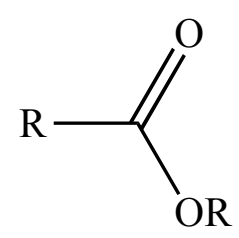

2

Amidines are strong bases (pKa ranges from 5-12). The protonation occurs on the imino nitrogen ${ }^{4,5}$ leading to symmetrical amidinium ion $\mathbf{3}$ which is stabilized by resonance as in the isoelectronic carboxylate anion 4.

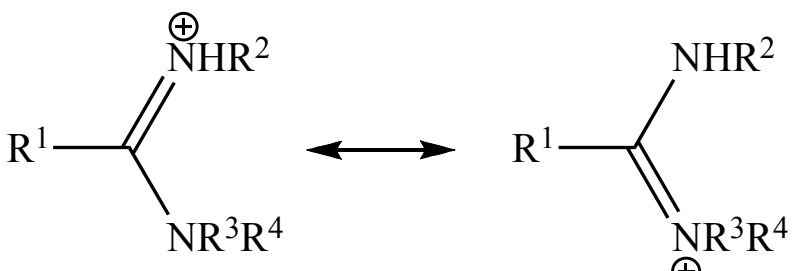

3

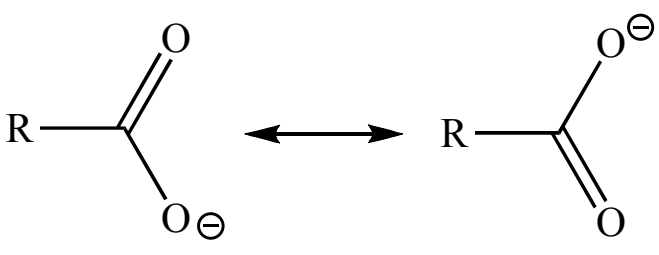

4

In a strong acidic media, the dication $\mathbf{5}$ is formed, which has a localized carbon-nitrogen double bond, whereas in a strong alkaline solution the anion $\mathbf{6}$ can be formed..$^{6-8}$

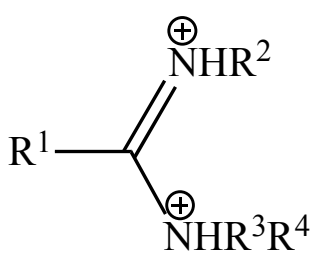

5

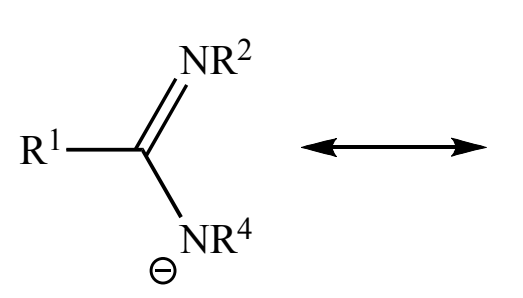

6

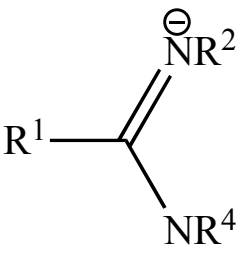




\section{Synthesis of Amidines}

Numerous methods have been reported for the preparation of amidines. ${ }^{9}$ The most common methods of amidine synthesis are from amides, nitriles and/or thioamides.

\subsection{Amidines from amides or carboxylic acids}

Amides can be converted to imidoyl chlorides using phosphorous pentachloride. The forming imidoyl chlorides can react with primary or secondary amines to yield amidines (Scheme 1). ${ }^{10}$ This method is generally poor for preparing unsubstituted amidines from primary amides, but it is an excellent general method for preparing di- and tri-substituted amidines. Other reagents such as phosphorous oxychloride or thionyl chloride can be employed in the synthesis of imidoyl chlorides but usually lower yields are obtained.

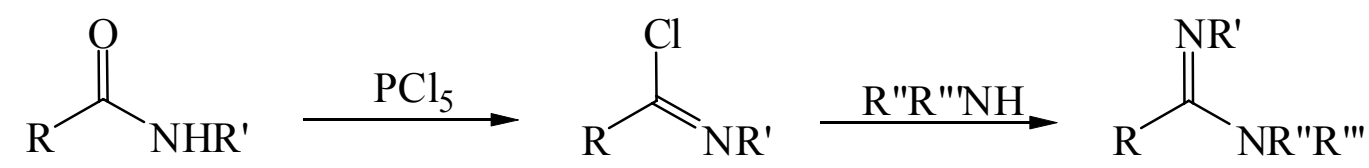

\section{Scheme 1}

Amides can be $o$-alkylated with triethyloxonium fluoroborate at ambient temperature to yield the corresponding imidic ester fluoroborates, which react with amines to yield the target amidines (Scheme 2). ${ }^{11}$
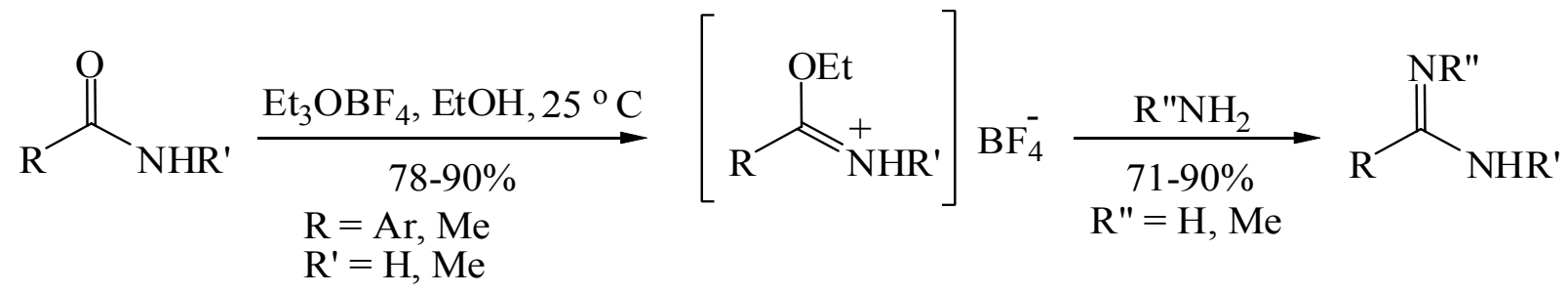

\section{Scheme 2}

Direct synthesis of amidines from carboxylic acids and amines can be performed via intermediate amides using polyphosphoric acid trimethylsilyl ester (PPSE), generated in situ from the reaction of phosphorus pentoxide with hexamethyldisiloxane as a condensing agent (Scheme 3). ${ }^{12}$ 


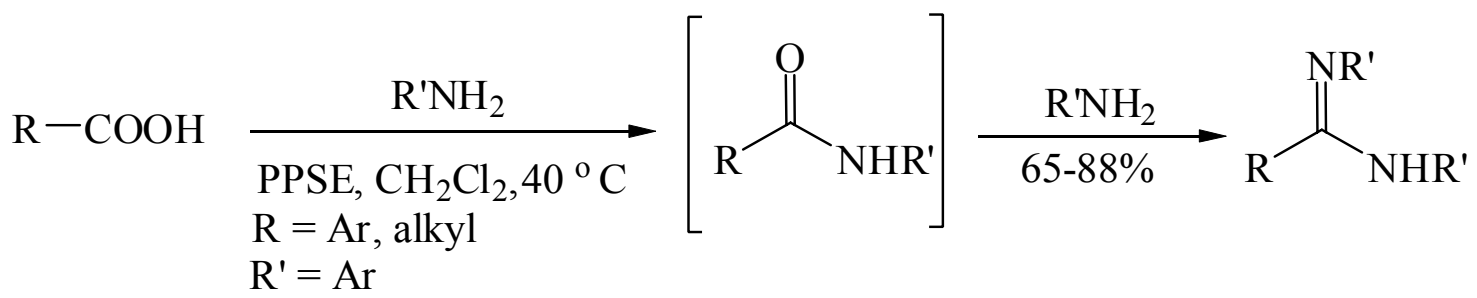

\section{Scheme 3}

\subsection{Amidines from nitriles}

Nitriles are activated to the intermediate salts in the presence of ethanol and hydrogen chloride under anhydrous conditions. The separated salts are then reacted with amines to generate the amidines shown in Scheme 4. ${ }^{13,14}$ This method can be also considered as the most widely used procedure for the preparation of unsubstituted amidines. The direct synthesis of amidines from nitriles and amines can only be achieved if nitriles are substituted by electron-withdrawing groups. ${ }^{15}$ Unreactive nitriles have been used to prepare amidines in the presence of Lewis acids such as $\mathrm{AlCl}_{3}$ or $\mathrm{ZnCl}_{2}$ at elevated temperatures of $150-200{ }^{\circ} \mathrm{C} .{ }^{16}$ Previously, it was shown that alkylchloroaluminum amides are useful reagents for the conversion of nitriles to amidines under milder conditions. ${ }^{16}$ It was found that ${ }^{17}$ addition of alkylchloroaluminum amides, generated conveniently from trimethyl aluminum and ammonium chlorides, to nitriles in warm toluene efficiently afforded the desired amidines in reasonable yields after hydrolysis of aluminum species as shown in Schemes 5 and 6.

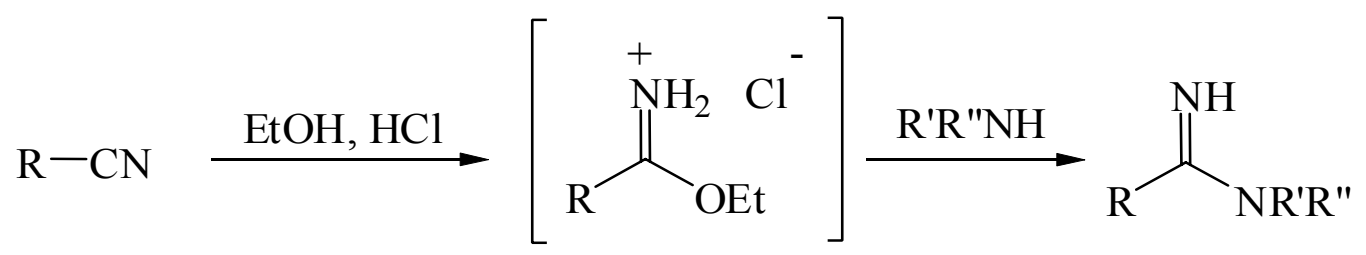

\section{Scheme 4}

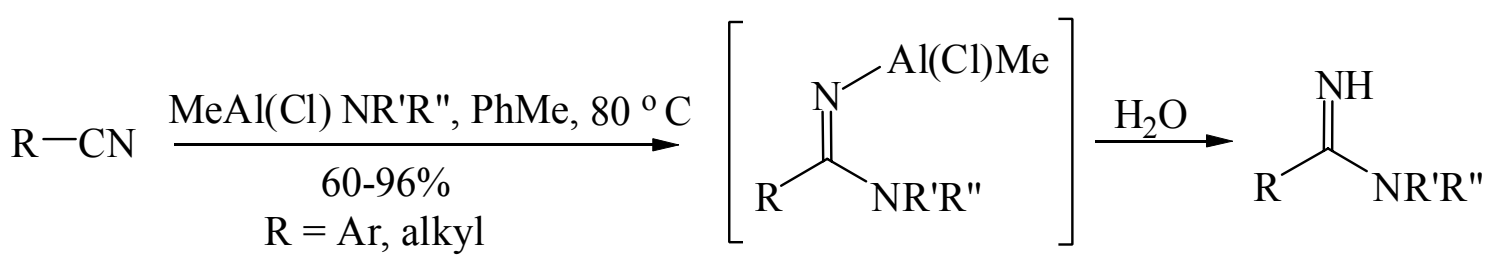

\section{Scheme 5}

Moss $^{18}$ demonstrated that reaction of methylchloroaluminum amide with sterically hindered nitriles 7-10 produced the corresponding amidines (Scheme 6). 


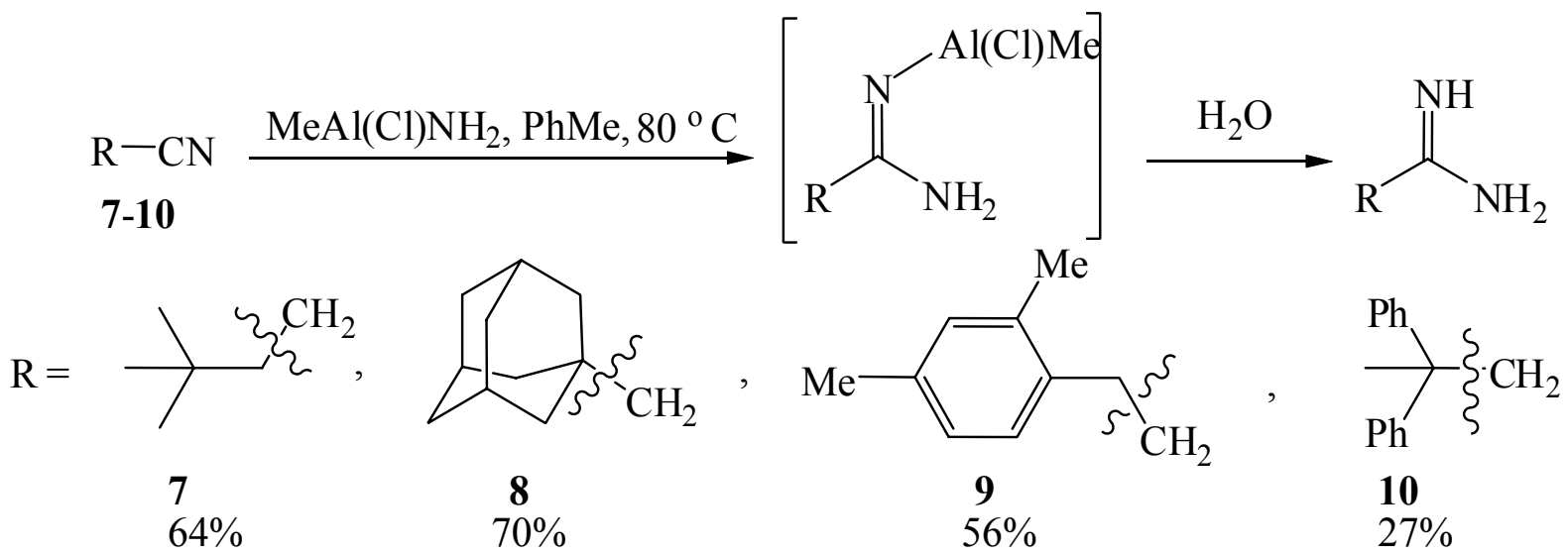

\section{Scheme 6}

A general preparation of amidines from unactivated nitriles has been reported. ${ }^{19}$ Stoichiometric copper(I) chloride induced addition of various amines to nitriles provided amidines in excellent yields (Scheme 7).

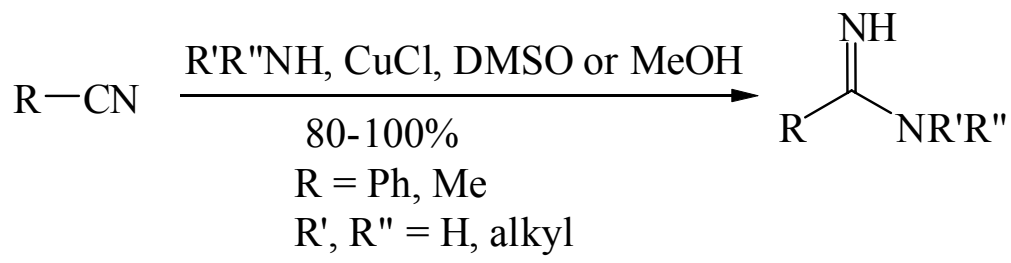

\section{Scheme 7}

Scheme 8 illustrates the catalytic use of Ln(III) ions in the addition of primary amines to unactivated nitriles to give intermediate mono-substituted amidines, which can react with another primary amine to yield di-substituted amidines. ${ }^{20}$

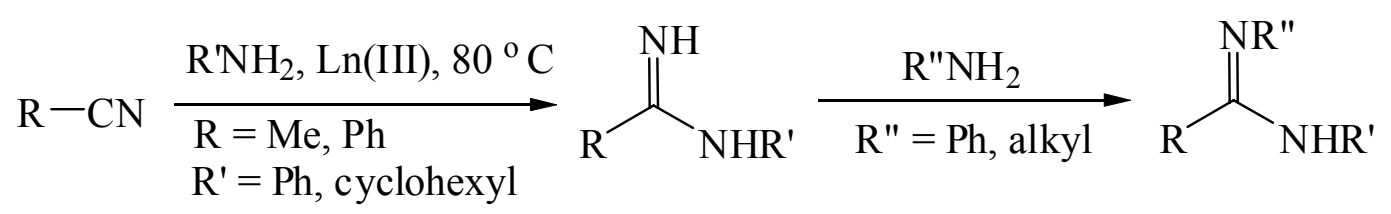

\section{Scheme 8}

Substituted benzonitriles were converted into intermediate benzamidoximes, which are then successfully reduced to benzamidines, via palladium-catalyzed hydrogenolysis in acetic acid/acetic anhydride mixture (Scheme 9). ${ }^{21}$ Acetic anhydride was found to be a necessary acylating agent in providing useful reaction rates in the hydrogenolysis step. 

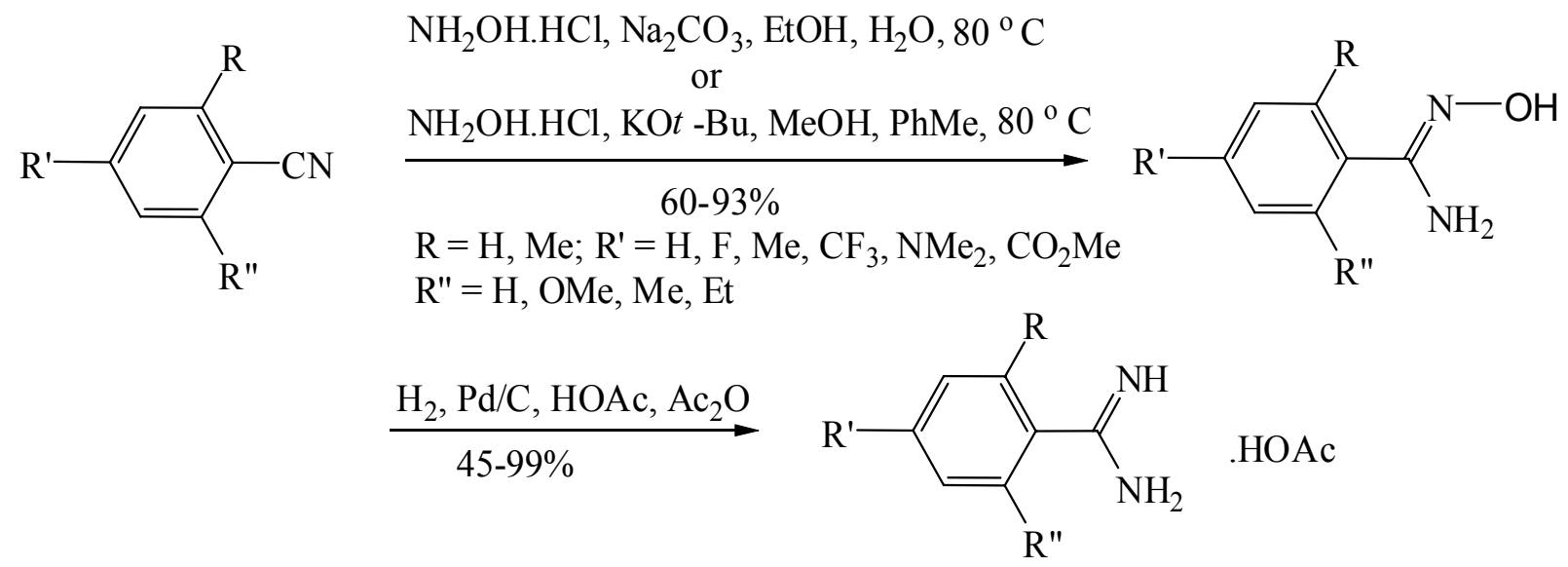

Scheme 9

Iron pentacarbonyl was employed to the conversion of amidoximes into amidines via reductive cleavage of the $\mathrm{N}-\mathrm{O}$ bond (Scheme 10). ${ }^{22}$

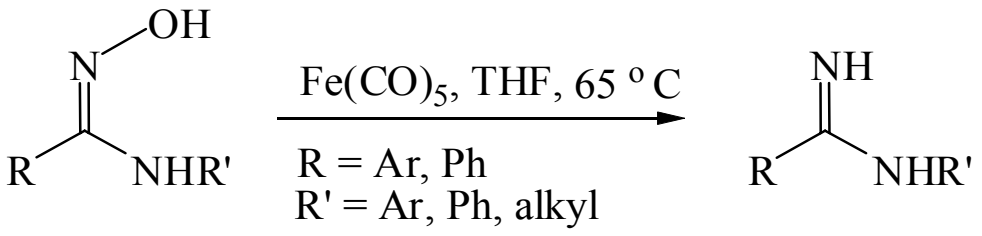

\section{Scheme 10}

Imidates were prepared from nitriles in the presence of thiophenol and $\mathrm{HBr}$ (Scheme 11). ${ }^{23}$ Phenylthioimidates were readily converted to amidine salts in the presence of various amines.

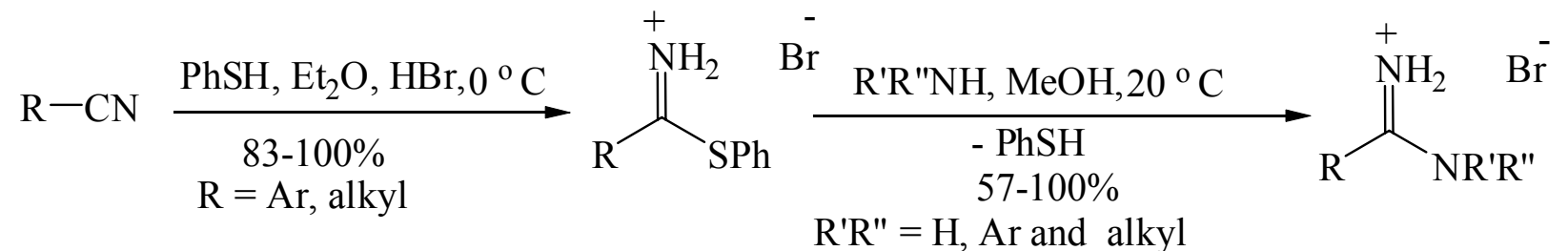

\section{Scheme 11}

Previously, it was shown that addition of primary amines to ethylthioimidates under acidic conditions provided amidines (Scheme 12). ${ }^{24}$ 

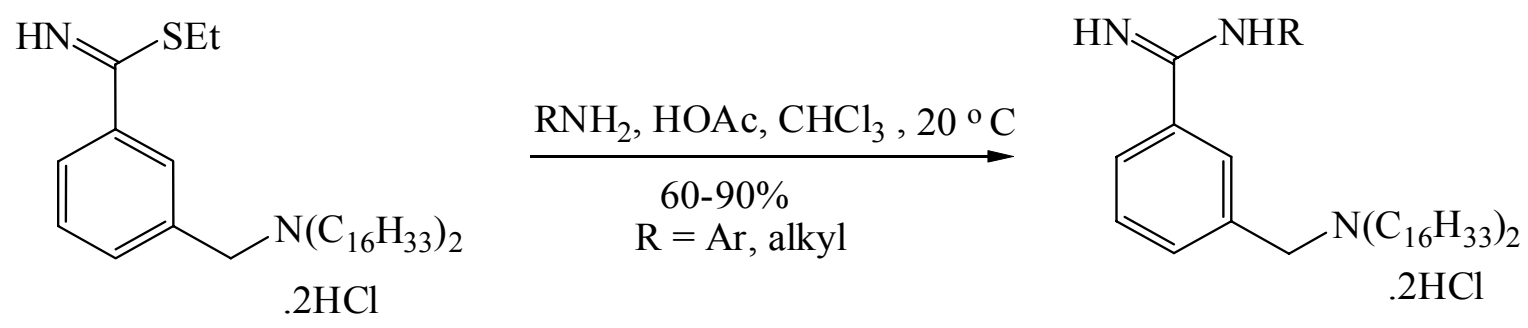

\section{Scheme 12}

Schäfer used $N$-acetylcysteine 11 to transform nitriles to thioimido intermediates 12, which reacted with ammonia to give amidine salts $\mathbf{1 3}$ (Scheme 13). ${ }^{25}$ The amidines are then isolated as their acetate salts via ion exchange.

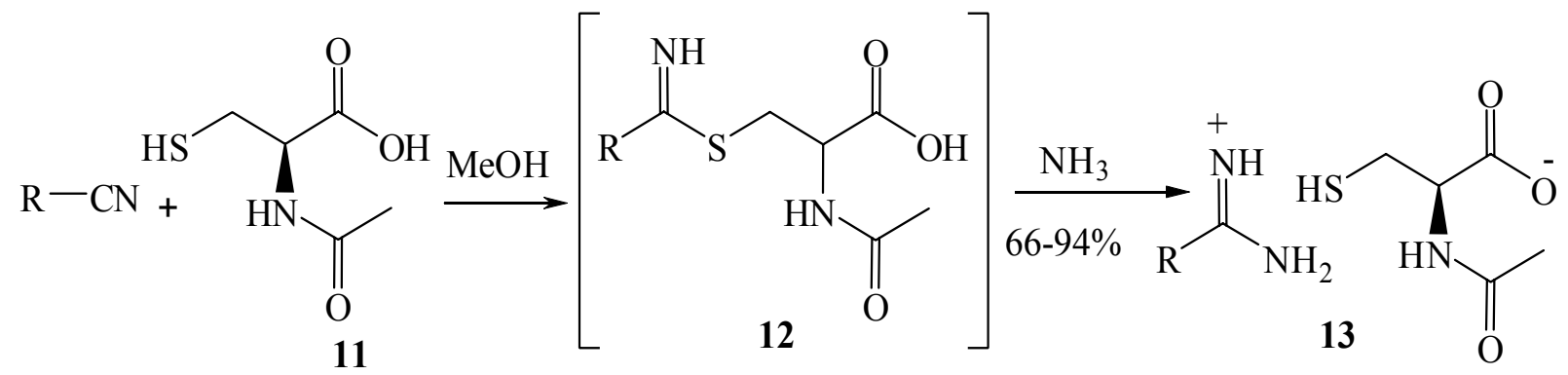

$\mathrm{R}=$ hetero, amino acid and alkyl

\section{Scheme 13}

An efficient synthesis of amidinoformic acids $\mathbf{1 8}$ has been published using benzyl cyanoformate (14) as a synthon. Compound 14 was converted to the thioamide 15 in the presence of hydrogen sulfide (Scheme 14). ${ }^{26}$ Thioamide 15 is $S$-alkylated with triethyloxonium tetrafluoroborate to afford thioamidate 16. Addition of one equivalent of amines to $\mathbf{1 6}$ furnished amidinoformic esters 17, which after hydrolysis provided with amidinoformic acids $\mathbf{1 8}$ (Scheme 14). 


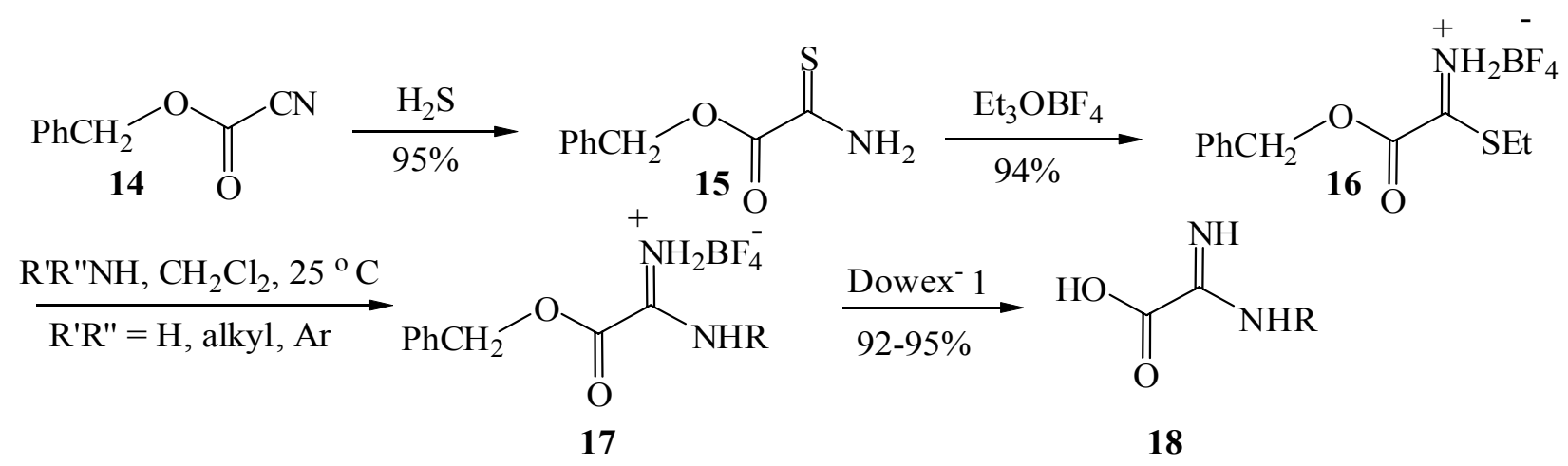

\section{Scheme 14}

\section{Cyclic Amidines}

Cyclic optically active amidines are strongly basic compounds which can serve as chiral reagents for NMR analysis of enantiomeric mixture of weakly acid compounds, or as ligands in catalysts for enantioselective synthesis. Enantiopure $\mathrm{C}_{2}$-chiral amidines $\mathbf{2 2}$ were synthesized from diamines 19 and $\Delta^{2}$-oxazolinium salts 20 or imidic ester salts 21 (Scheme 15). ${ }^{27}$

An interesting synthesis of cyclic amidine $\mathbf{2 4}$ from diamines $\mathbf{2 3}$ using trimethylorthoformate and formic acid at $100^{\circ} \mathrm{C}$ was also reported (Scheme 16). ${ }^{28}$

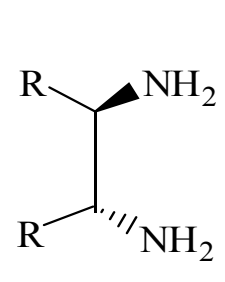

19

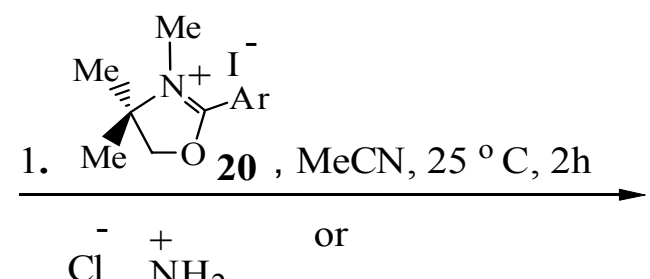

$\mathrm{EtOH}, 25^{\circ} \mathrm{C}, 4 \mathrm{~h}$

2. $5 \% \mathrm{Na}_{2} \mathrm{CO}_{3}$

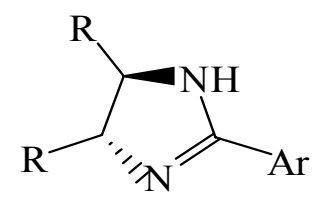

22

$(83-97 \%)$

\section{Scheme 15}
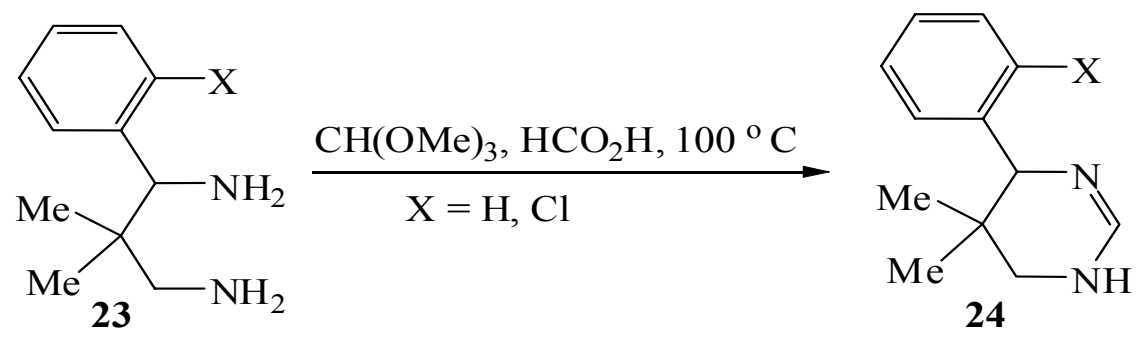

\section{Scheme 16}


A potent mannosidase amidine inhibitor $\mathbf{2 6}$ was prepared from $D$-mannose based lactam $\mathbf{2 5}$ via the intermediate thiolactam, which was then reacted with benzylamine (Scheme 17). ${ }^{29}$

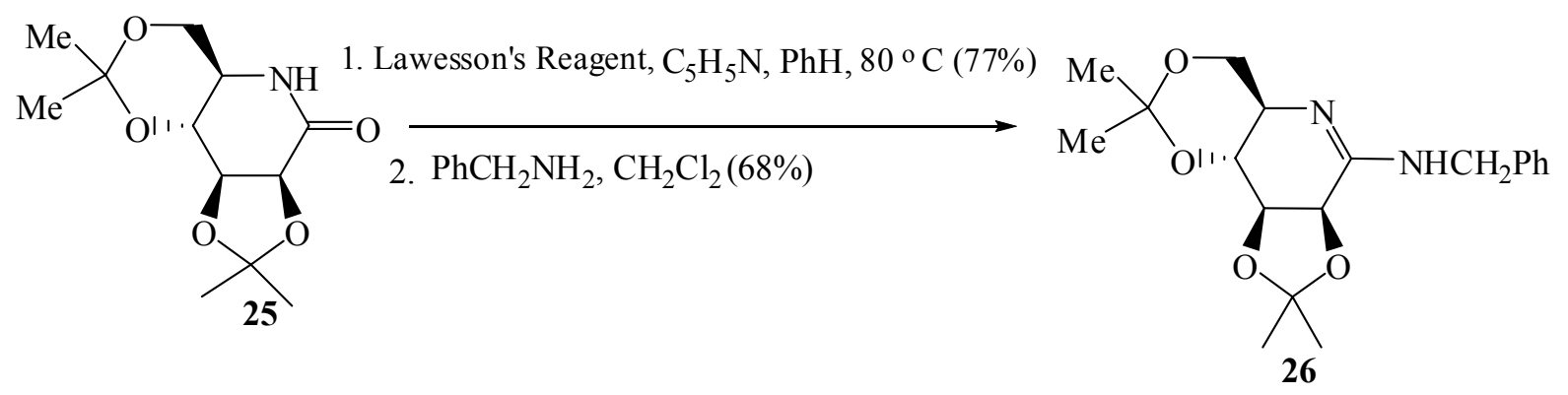

\section{Scheme 17}

Thionolactam 27 was converted to amidines $\mathbf{2 8}$ in the presence of methanolic ammonia and mercuric oxide (Scheme 18). ${ }^{30}$

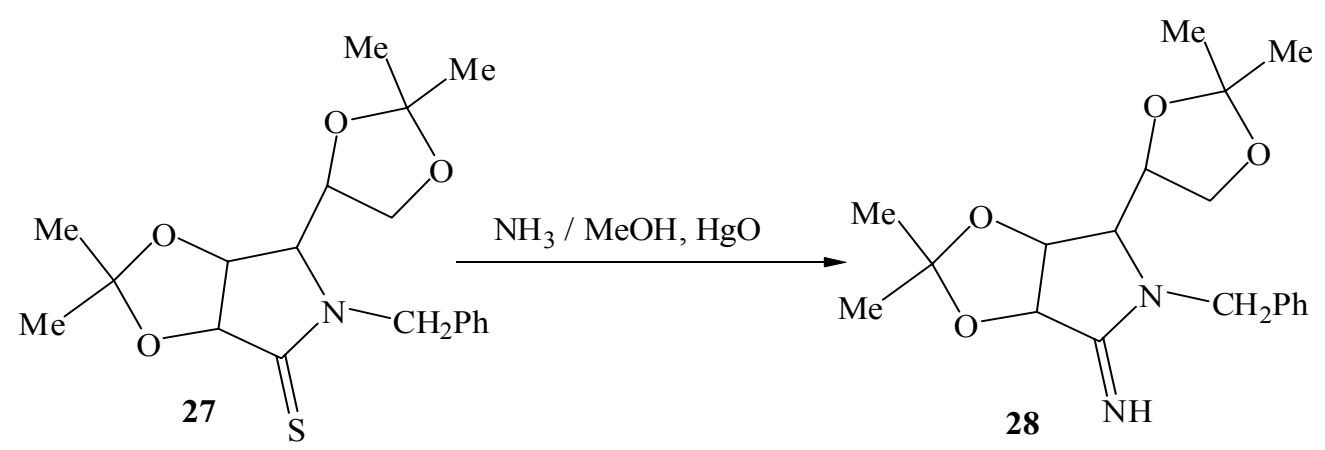

\section{Scheme 18}

Similarly, amidines 30, derivatives of $D$-glucose were prepared from the reaction of thiolactam 29 as part of a study of inhibiting glycosidases (Scheme 19). ${ }^{31}$ A one-flask synthesis of 2-diethylamino-3-oxo-3H-indole (32) was prepared by the action of oxygen copper-catalyzed oxidation on $1 H$-indole (31) (Scheme 20$){ }^{32}$

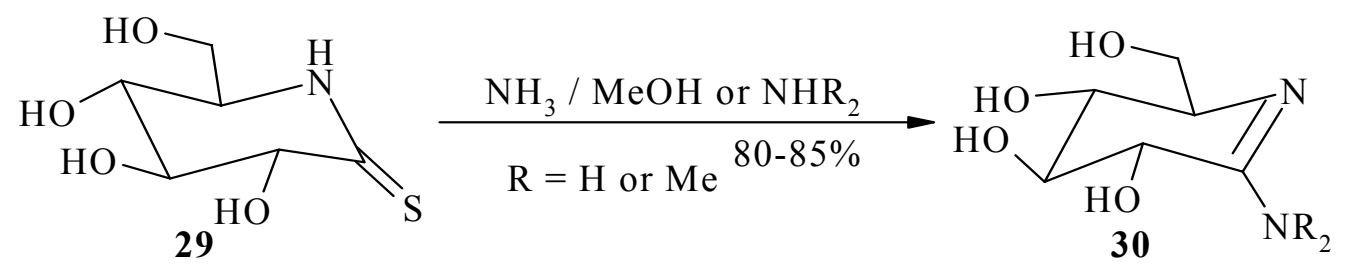

\section{Scheme 19}




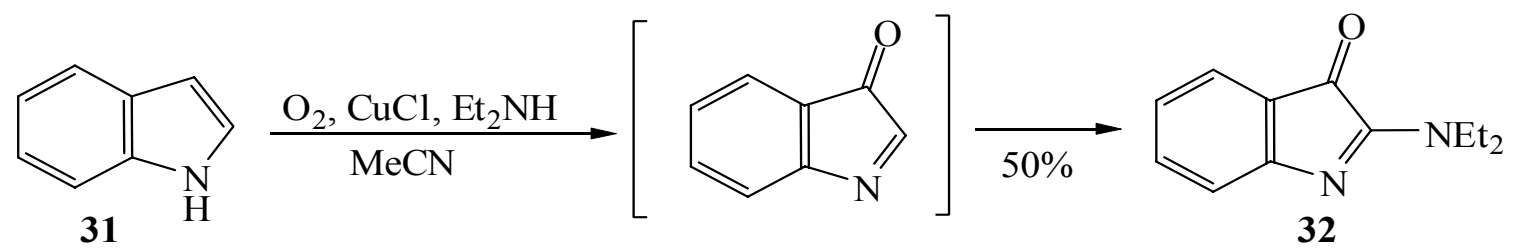

\section{Scheme 20}

Bis-nitriles react with ethylenediamine and dry hydrogen sulfide in refluxing ethanol to afford cyclic diamidines 33 (Scheme 21). ${ }^{33}$ Mechanistically, the addition of hydrogen sulfide to the cyano groups of bis-nitriles afforded the corresponding bis-thioamides as shown in Scheme 21. Addition of ethylenediamine to the bis-thioamides afforded the intermediate $\mathbf{3 4}$ after expulsion of ammonia. Finally, intramolecular cyclization of intermediate $\mathbf{3 4}$ provided $\mathbf{3 3}$ after elimination of hydrogen sulfide (Scheme 21).

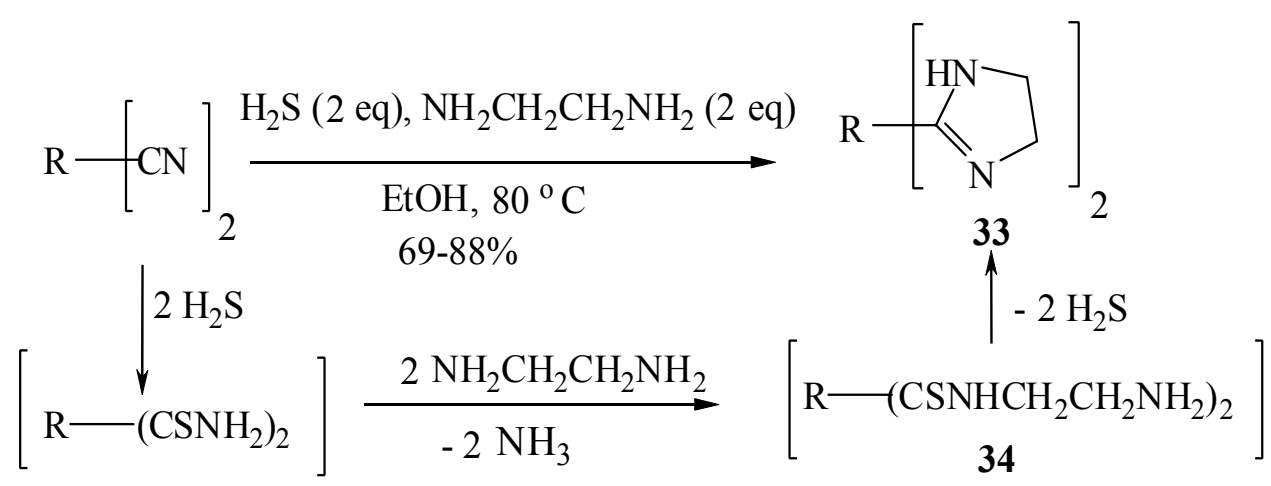

\section{Scheme 21}

\section{Miscellaneous Amidines}

The reaction of compound 35 with alcohols under Mitsunobu conditions gave amidines 36, which after hydrogenolysis afforded free amidines as noted in Scheme 22. Another synthetic approach to substituted amidines was established during the reactions of $\mathbf{3 5}$ with amines to give 37 followed by hydrogenolysis (Scheme 22). 


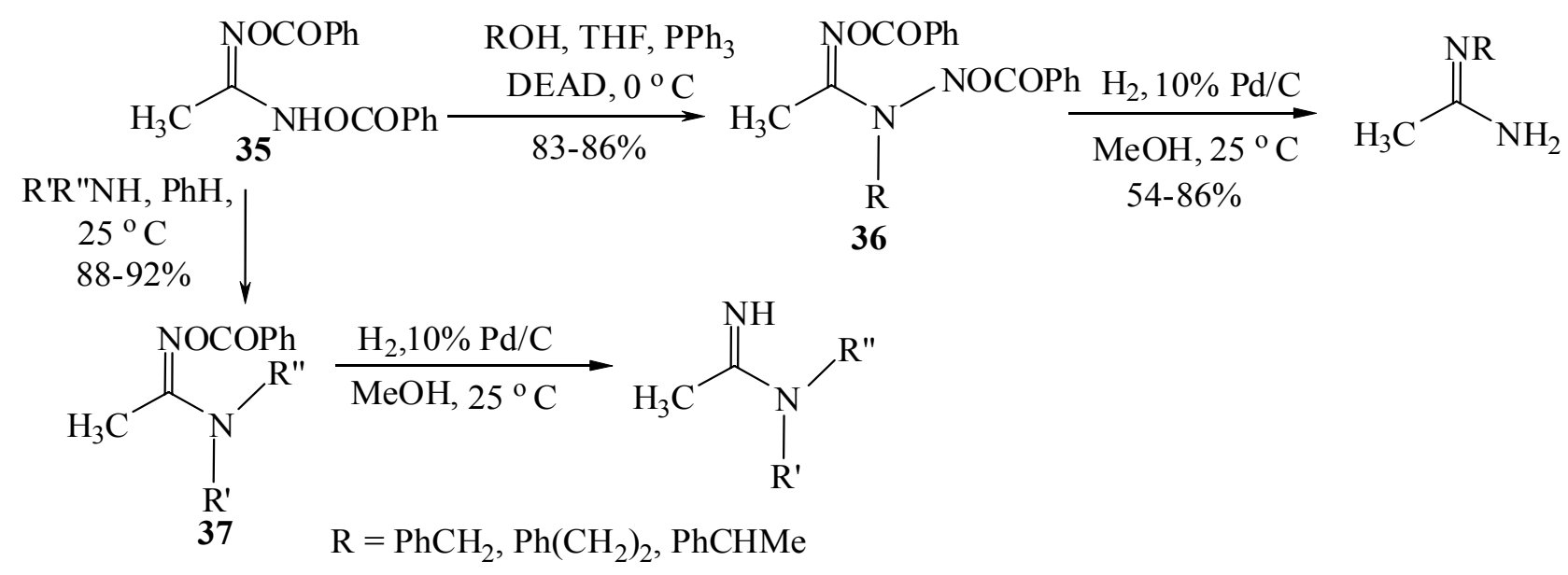

Scheme 22

Seyferth showed the direct nucleophilic acylation of carbodiimides $\mathbf{3 8}$ with alkyllithiums and carbon monoxide to give intermediate 39 (Scheme 23). Neutralization of 39 with an acid afforded the $\alpha$-oxo-amidines given in Scheme $23 .^{35}$

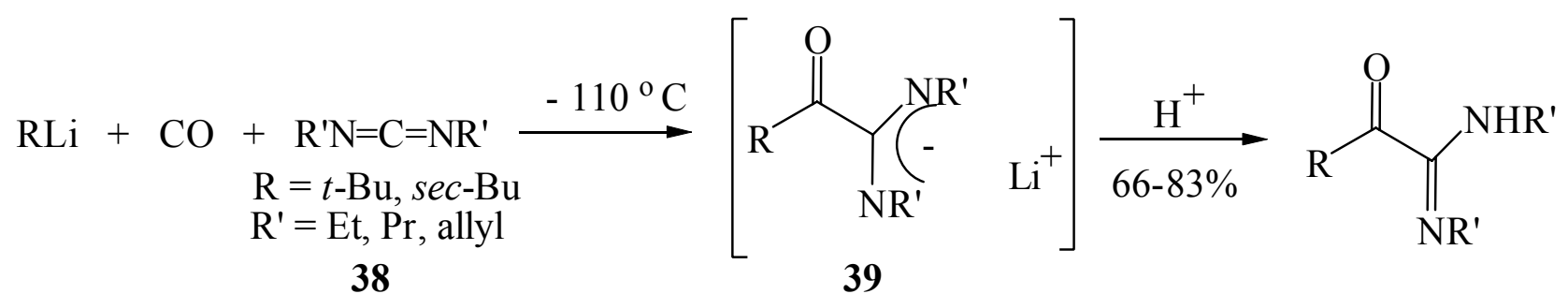

\section{Scheme 23}

\section{Amidines as Building Blocks in Synthesis}

\subsection{Synthesis of amidrazones and amidoximes}

The use of ammonia or amines in excess at high temperatures can displace one of the nitrogens of the amidino group (Scheme 24). ${ }^{36,37}$<smiles>[R1]N=C([R])N[R]</smiles>

\section{Scheme 24}


Similar equilibria are also established with certain derivatives of ammonia such as hydrazines and hydroxylamines, e.g., phenylhydrazine hydrochloride heated with amidines yields amidrazones (Scheme 25). ${ }^{38,39}$<smiles>NC([Al])=Nc1ccccc1</smiles>

\section{Scheme 25}

Hydroxylamine gives amidoximes (40a, Scheme 26), ${ }^{36,38,40,41}$ but in practice this reaction is not useful, since amidines like $\mathbf{4 0 b}$ are generally obtained from iminoethers (Scheme 26$){ }^{42}$

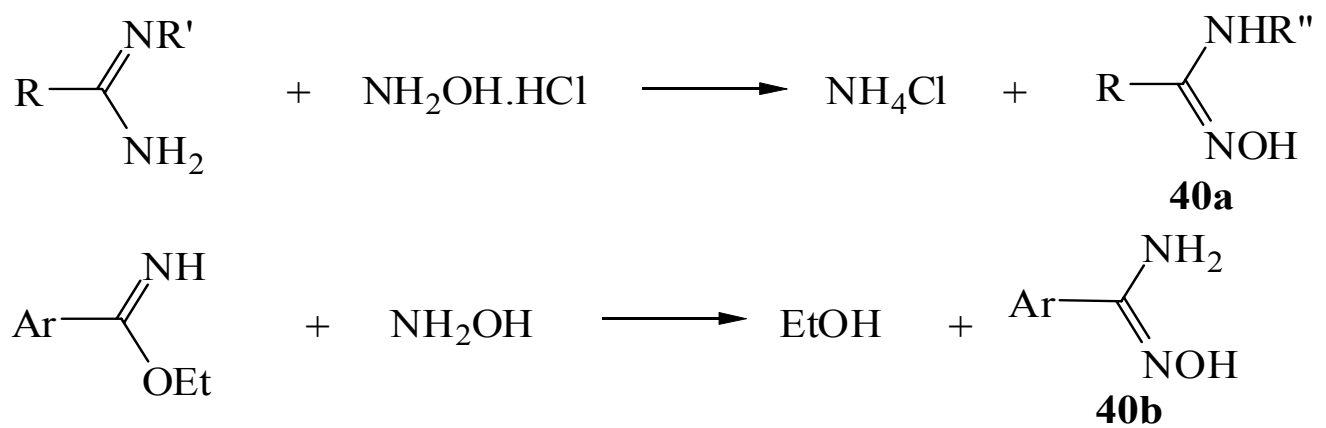

\section{Scheme 26}

\subsection{Synthesis of heterocyclic derivatives}

Cyclization is the most important reaction of amidines leading to various heterocyclic compounds containing the $-\mathrm{N}=\mathrm{C}-\mathrm{N}=$ group.

4.2.1 Synthesis of three-membered rings. The halogenation of alkyl- or aryl-amidines by using sodium hypochlorite in aqueous dimethyl sulfoxide solution affords the corresponding alkyl-, or aryl-3-halodiazirine 41 (Scheme 27). ${ }^{43}$<smiles>[R]C(=N)N</smiles>

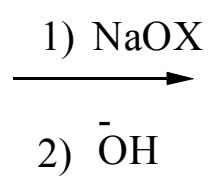<smiles>[X]C1([R])N=N1</smiles>

\section{Scheme 27}


4.2.2 Synthesis of four-membered rings. The cycloaddition of diphenylketene (42) with 4-(Nphenylformimidinoyl)moropholine (43) resulted in the formation of crystalline 1,3,3-triphenyl-4morpholino-azetidinone (44) (Scheme 28). ${ }^{44}$<smiles>O=C=C(c1ccccc1)c1ccccc1</smiles>

42<smiles>C(=Nc1ccccc1)N1CCOCC1</smiles>

\section{Scheme 28}

The reaction of diphenylketene $\mathbf{4 2}$ with disubstituted amidines was attempted. Most of the formed $\beta$-lactams were very sensitive to moisture which led to their decomposition. ${ }^{44}$ Addition of 42 to a disubstituted amidine led only to an amide 45 (Scheme 29). ${ }^{44}$<smiles>CC(=Nc1ccccc1)N(C(=O)OC(C)c1ccccc1)c1ccccc1</smiles>

\section{Scheme 29}

\subsubsection{Synthesis of five-membered rings}

4.2.3.1. Pyrrole derivatives. Cyclization of $N^{\prime}$-tolyl- $N$-methyl- $N$-phenylformamidine (46) to $1 H$ indole (31) occurs on heating a mixture of $\mathbf{4 6}$ and sodium amide at $300{ }^{\circ} \mathrm{C}$. The mechanistic steps are outlined in Scheme 30. ${ }^{45}$<smiles>Cc1ccccc1/N=C/N(C)c1ccccc1</smiles>

46

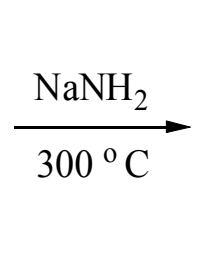<smiles>CN(C)c1ccccc1</smiles>

\section{Scheme 30}

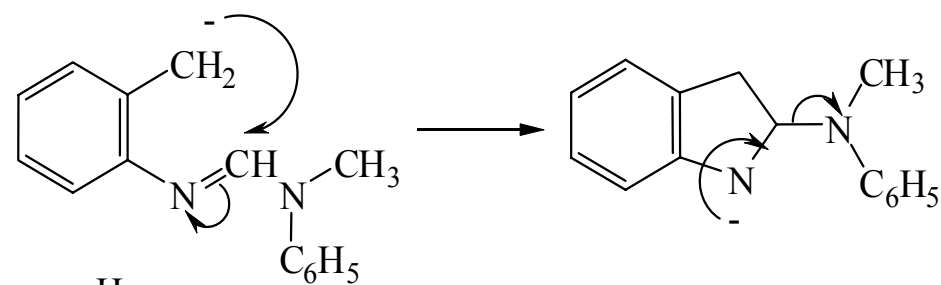<smiles>C[PH+](F)c1ccc2cc[nH]c2c1</smiles>

31 
4.2.3.2 Oxazole derivatives. Interestingly, heating $N$-phenyl- $N^{\prime}(o$-hydroxyphenyl)benzamidine, at $100{ }^{\circ} \mathrm{C}$ for $30 \mathrm{~min}$ leads to the formation of 2-phenyl-benzoxazole (47, Scheme 31$){ }^{46}$

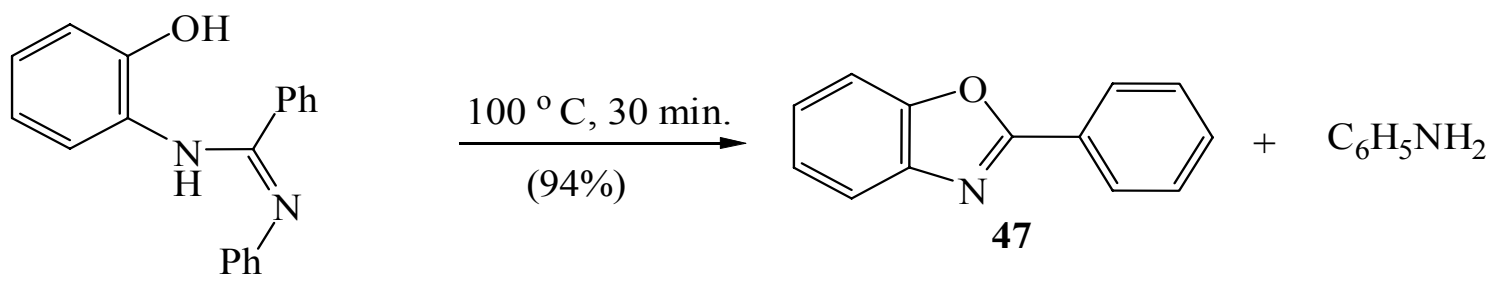

\section{Scheme 31}

4.2.3.3 Thiadiazole derivatives. From $N$-imidoylthioureas 49, as amidine derivatives (prepared from the reaction of $\mathrm{N}$-imidoyl chlorides $\mathbf{4 8}$ with sodium thiocyanide and amines), thiadiazoles 51 can be easily obtained (Scheme 32 ). ${ }^{47,48}$

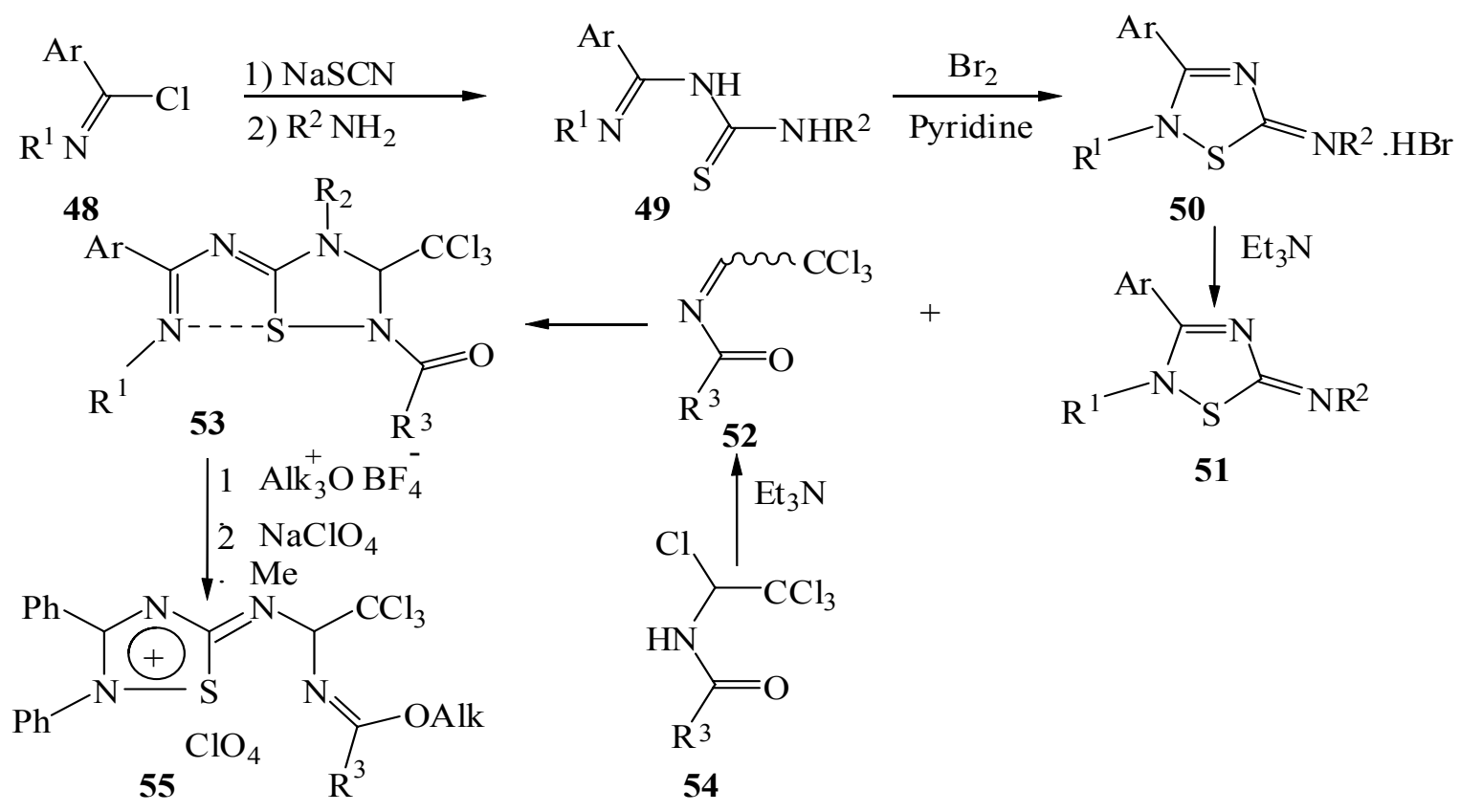

\section{Scheme 32}

The most interesting feature of the obtained thiadiazoles $\mathbf{5 1}$ is the ability to take part in $[3+2]$ cycloaddition reactions as 1,3 -dipoles, ${ }^{49,50}$ as illustrated by the cycloaddition to $N-(2,2,2-$ trichloro-ethylidene)-substituted carboxamides and carbamates 52 (Scheme 32). ${ }^{51}$ 
<smiles>N#CC(C#N)=C1C(=O)c2ccccc2C1=O</smiles>

A

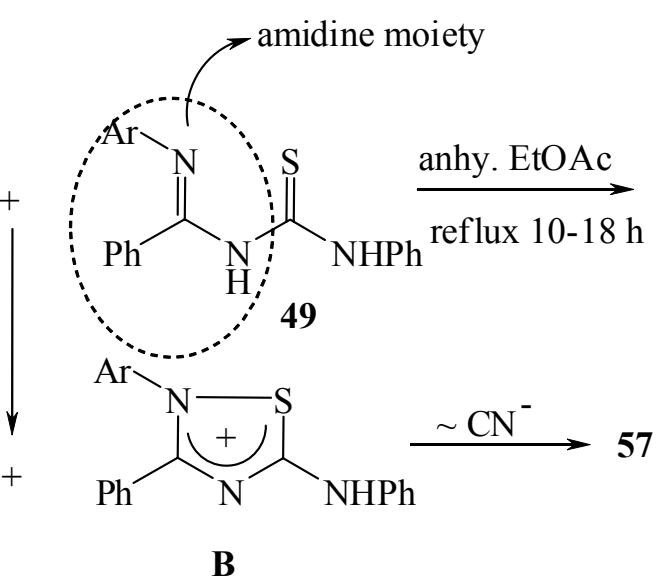

B<smiles>N#CC1(Nc2ccccc2)N=C(c2ccccc2)N([Al])S1</smiles><smiles>CC(C)=C1C(=O)c2ccccc2C1=O</smiles>

\section{Scheme 33}

4.2.4 Synthesis of six-membered rings. Recently, the syntheses of various 1,2,4-thiadiazole-5carbonitriles from the reaction of $N$-imidoylthioureas 49 with 2-(1,3-dioxoindan-2ylidene)malononitrile (56) has been reported. The proposed mechanism for the formation of thiadiazoles 57 is thought to involve the initial oxidation of 49 by the acceptor 56. Oxidation process is accompanied by a formal hydride transfer process generating species $\mathbf{A}$ and $\mathbf{B}$ (Scheme 33). The intermediates $\mathbf{B}$ pick up cyanide anion from $\mathbf{A}$ to form product $\mathbf{5 7} .{ }^{52}$

4.2.4.1 Pyridines. The malononitrile dimer reacts with the formamidine acetate as well as acetamidine hydrochloride affording 2,4-diamino-3,5-pyridinedicarbonitriles 59. This reaction proceeds through the elimination of ammonia to give $\mathbf{5 8}$ which is cyclized into $\mathbf{5 9}$ (Scheme 34 ). ${ }^{53}$<smiles>[R][R]C(C)(C)N(C)N</smiles>

\section{Scheme 34}


4.2.4.2 Pyrimidines. Unsubstituted amidines easily condense with $\beta$-ketoesters in presence of sodium ethoxide to yield pyrimidine 60 (Scheme 35). ${ }^{54}$ Similarly, formamidine reacts with ethylmalonate to yield 4,6-dihydroxypyrimidine (61, Scheme 35$).^{55}$

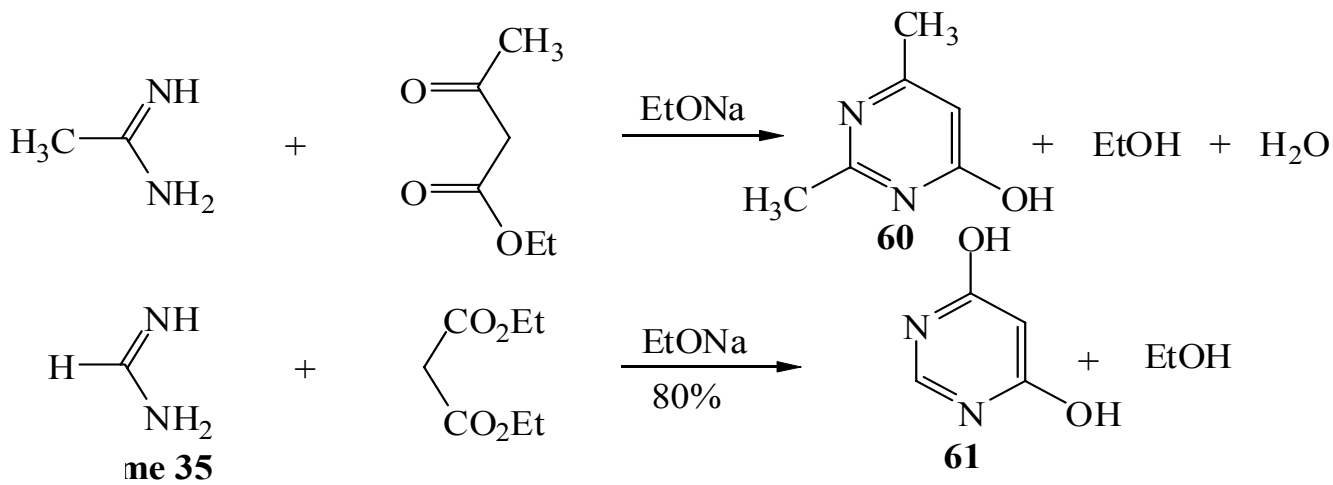

\section{Scheme 35}

4.2.4.3 Triazines. $s$-Triazine (62) can be obtained by heating formamidine hydrochloride. ${ }^{56,57}$ The reaction also gives good yields with trichloroacetamidine (Scheme 36). ${ }^{57}$<smiles>N=CN</smiles><smiles>NNC(=O)O</smiles>

\section{Scheme 36}

4.2.4.4 Tetrazines. 1,2,4,5-Dihydrotetrazines 63 were prepared by action of monosubstituted amidines on hydrazine hydrate (Scheme 37$).^{58}$<smiles>[R]C(=N)N</smiles><smiles>N#CCN</smiles><smiles>[R]C1=NN=C([R])NN1</smiles>

63

\section{Scheme 37}

4.2.4.5 Oxazines and thiadiazines. Reaction between phenyl salicylate and $N$-phenylbenzamidine yielded 2-phenyl-benzoxazine (65). The mechanistic steps can be discussed on the basis of the formation of the condensed product 64, which cyclizes and, after elimination of aniline, affords 65 (Scheme 38). ${ }^{59}$ 


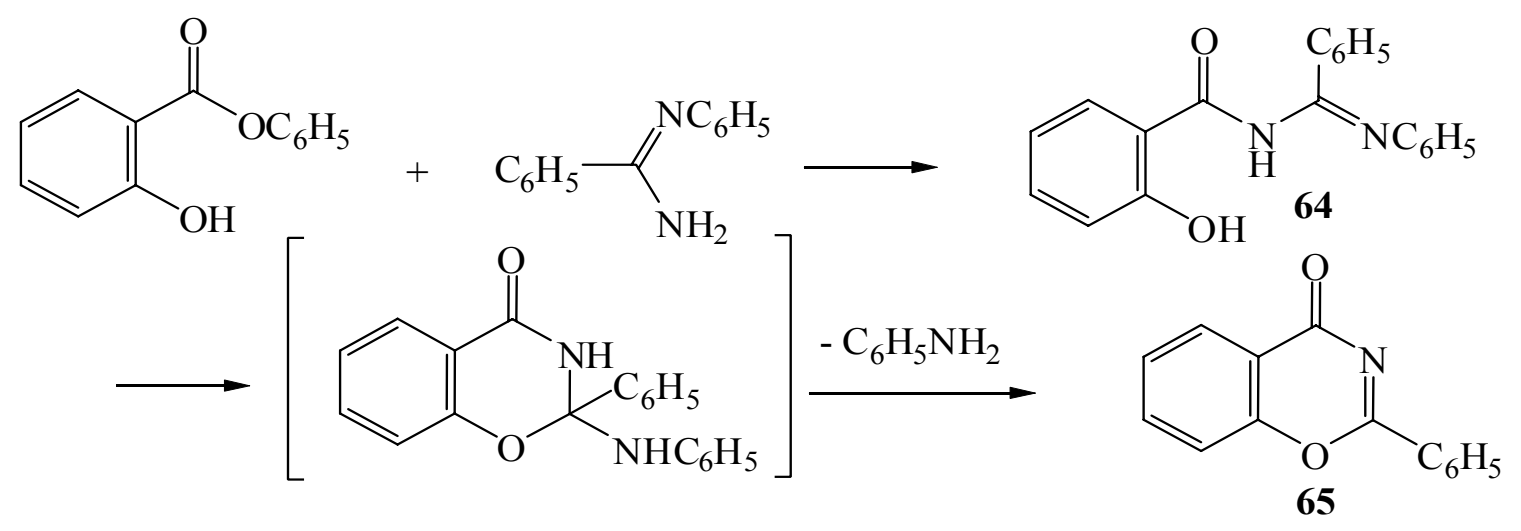

\section{Scheme 38}

4.2.4.6 Synthesis of cycloaminals of trichloroacetaldehyde. Remarkably, the conversion of one $=\mathrm{NH}$ fragment into a carbonyl group via a hydrolysis reaction has been reported (Scheme $39) .{ }^{60-63}$<smiles>O=C1NC(C(Cl)(Cl)Cl)N=C1N[Al]</smiles>

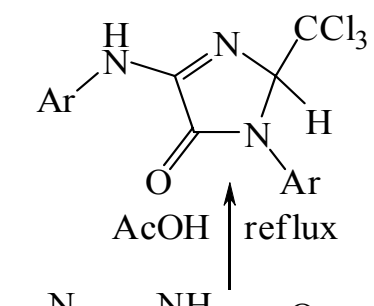<smiles>N=C(NC1=NC(C(Cl)(Cl)Cl)NC1=N[Al])C(N)=N[Al]</smiles>

\section{Scheme 39}

4.2.4.7 Synthesis pyrimidin-4(3H)-ones. Aly and co-workers demonstrated that 2,3-diphenylcyclopropenone (66) reacted with $N$-imidoyl-thioureas 49 to form the pyrimidin-4(3H)-ones 67 (Scheme 40). ${ }^{64}$ 


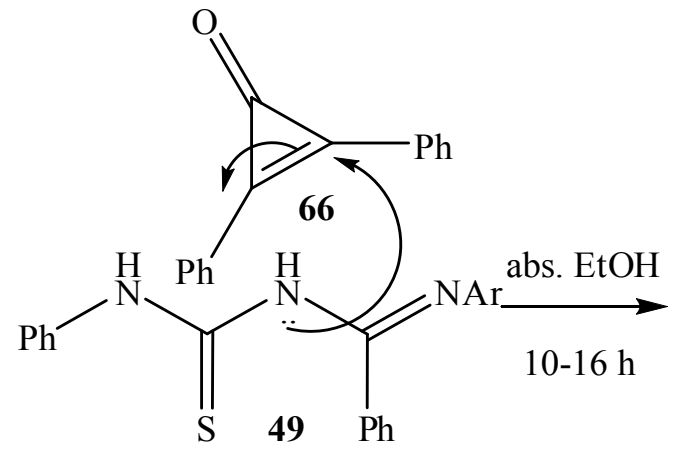<smiles>O=c1c(-c2ccccc2)c(-c2ccccc2)nc(-c2ccccc2)n1[AlH2]</smiles>

$\mathrm{PhNH}=\mathrm{C}=\mathrm{S}$

\section{Scheme 40}

4.2.4.8 Synthesis of [2-arylamino-4(1H)-pyridinylidene]propanedinitriles. The synthesis of 1,4-dihydropyridines 69 with four or five substituents from the reaction of $N^{l}, N^{2}$-diarylamidines and (2,3-diphenylcyclopropen-1-ylidene)propandinitrile (68) by refluxing equimolar amounts of reactants in $N, N$-dimethylformamide (DMF) as solvent has been reported (Scheme 41). ${ }^{65}$<smiles>[R4]CC(=[W])N[141I]</smiles><smiles>[R]C1=C(N[AlH2])N([Al])C(c2ccccc2)=C(c2ccccc2)C1=C(C#N)C#N</smiles>

69

\section{Scheme 41}

Aly and co-workers reported the reaction of compounds 49 with 1,1,2,2-tetracyanoethylene (70) affording thiadiazepines 71 in $85-68 \%$ yields (Scheme 42 ). ${ }^{66}$ Presumably, the CT-complexes are transient intermediates for that reaction. Whereas the reactions of 49 with dimethyl acetylenedicarboxylate (DMAD, 72) were carried out in acetic acid at reflux temperature and afforded the 1,3,5-thiazepines 73 in $65-84 \%$ yields (Scheme 43 ). ${ }^{67}$ 


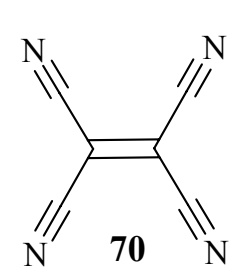

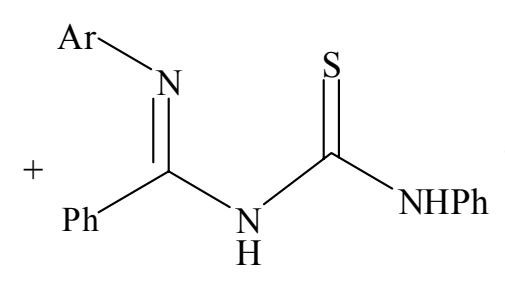

49

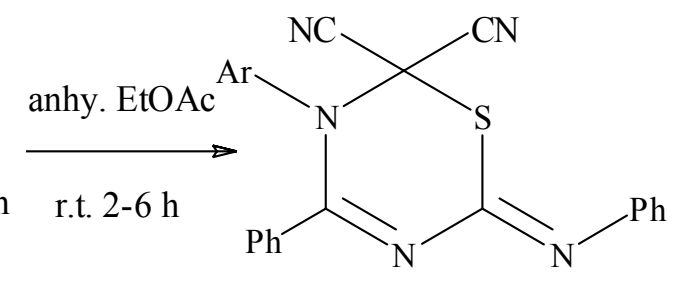

71

\section{Scheme 42}

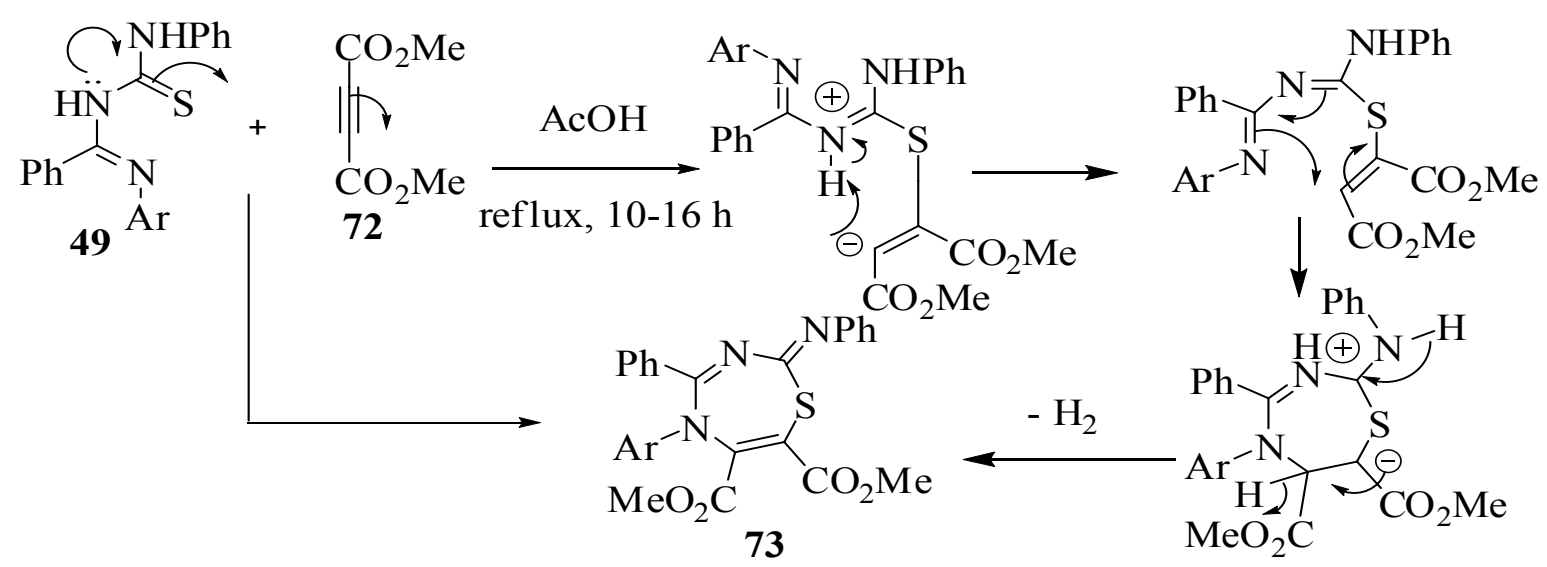

Scheme 43

\section{Amidrazones}

Amidrazones are weak monoacid bases characterized by the structural formula 74, where R, R', R", R"' and R'"' can be any of a wide variety of atomic or organic moieties. A particularly wellknown example of this class of compounds is aminoguanidine $\mathbf{7 5}$.

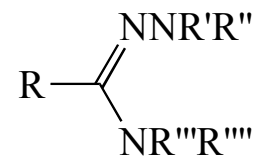

74<smiles>NC(N)=[NH2+]</smiles>

75<smiles>[R]C(=N)NN</smiles>

76<smiles>[R12]N=C([R])[R12]</smiles>

77<smiles>[R]C(=[W])N[W]=C([R])[R]</smiles>

78 
The nomenclature applied to compounds of type $\mathbf{7 4}$ has been somewhat confusing, and sometimes the name hydrazidine ${ }^{68-70}$ has also been used. Besides this, the name hydrazidine has been applied to compounds of type $\mathbf{7 6}$ which are also termed as hydrazide-hydrazones or dihydroformazans. These names cover, respectively, amidrazones of the types 77 and $\mathbf{7 8}\left(\mathrm{R}^{\prime} \neq \mathrm{H}\right)$ which are incapable of tautomerism. It is intended to adhere to the name amidrazone for all compounds of type $\mathbf{7 4}$ and furthermore to employ the nomenclature introduced by Rapoport and Bonner $^{71}$ as it is the least ambiguous. Amidrazone is named after the acid theoretically obtained from it by hydrolysis. ${ }^{71}$ Hence, $\mathrm{CH}_{3} \mathrm{C}\left(=\mathrm{NNH}_{2}\right) \mathrm{NH}_{2}$ is acetamidrazone, In addition, in compounds containing $N$ substituents, the nitrogen atoms are numbered ${ }^{71}$ as shown in formula 79 which is therefore named $N^{l}$-phenyl- $N^{l}, N^{3}, N^{3}$-trimethylpropionamidrazone. Compound 80 is thus a true diamidrazone (oxaldiamidrazone).
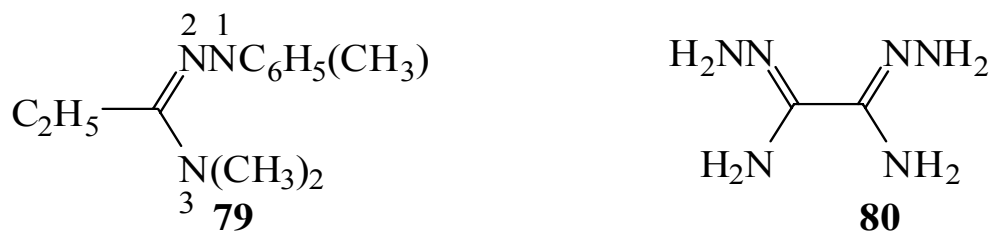

Related compounds having the structure of $\mathbf{8 1}$ were initially termed dihydrazidines, but have become known as amide-azines. ${ }^{72}$ Again difficulty arises with these compounds when their structures preclude tautomerism (e.g., compound 82, $\mathrm{R}=\mathrm{C}_{6} \mathrm{H}_{5} ; \mathrm{R}^{\prime}=\mathrm{CH}_{3}$ ), and it may well be more convenient to consider compounds 81 and 82 as $N, N^{\prime}$-diamidines. Formula 81 thus represents $N_{l}, N_{l}{ }^{\prime}$-dimethyl- $N_{2}, N_{2}{ }^{\prime}$-diphenyl- $N_{l}, N_{l}$-diformamidine. Otherwise, these compounds might be described as 1,2-seco-4,5-dihydro-syn-tetrazines 82 or diazabutadienes $\mathbf{8 1}$.

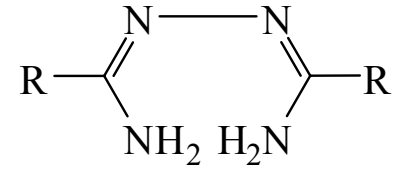

81

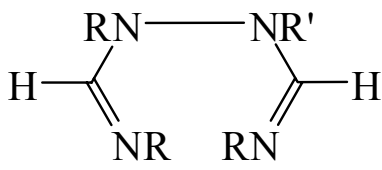

82

\subsection{General properties}

Amidrazones are, in general, monoacid bases which form salts with inorganic acids, the hydrochlorides being most commonly described, although carbonates, nitrates, picrates, benzoates, sulfates, and chloroplatinates have all been reported. ${ }^{72-74}$ In the free state, amidrazones tend to be either liquids or low-melting solids, and unsubstituted amidrazones show strong reducing properties akin to hydrazine itself. ${ }^{75}$ Indeed these amidrazones are almost unknown in the free state, the perfluoroalkyl compounds being almost unique in having been successfully characterized. ${ }^{76}$ Thus amidrazones in general tend to be unstable in alkaline solution undergoing hydrolysis but are much more stable in acid; ${ }^{77,78}$ e.g., heating $N^{l}$-phenylcyanoformamidrazone at 
$100{ }^{\circ} \mathrm{C}$ for a few hours in concentrated hydrochloric acid solution caused only slight decomposition of the amidrazone group (Scheme 44). ${ }^{78}$

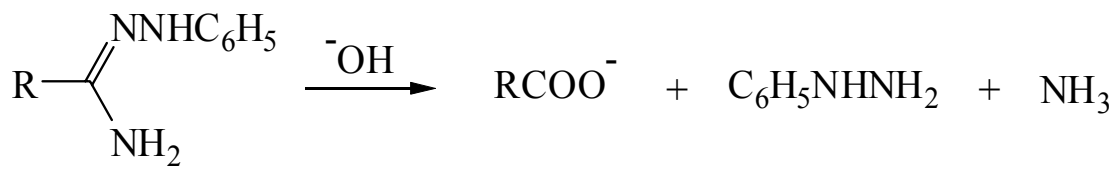

\section{Scheme 44}

The enhanced stability of the ion over that of the free base can be seen in the light of resonance theory which has been applied to the closely related amidines. ${ }^{79}$ The free amidrazones can be looked on as mesomeric, but the charge separation in structure 83b suggests that it does not contribute greatly to the resonance hybrid $(\mathbf{8 3 a} \leftrightarrow \mathbf{8 3 b})$.

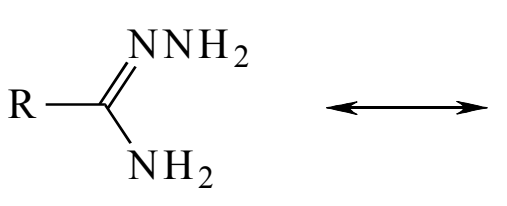

$83 \mathbf{a}$

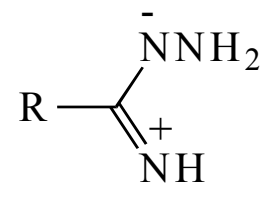

$83 b$

Spreading of the charge between $\mathbf{8 4 a} \leftrightarrow \mathbf{8 4 b}$ leads to enhanced stability.<smiles></smiles>

84a<smiles>[R]C(=[NH2+])NN</smiles>

84b<smiles>[R]C(=[NH2+])NN</smiles>

Little quantitative work appears on the measurement of the base strengths of amidrazone, however, $\mathrm{K}_{\mathrm{b}}$ for compounds of type $\mathbf{8 5}$ has been reported to be between $9.34 \cdot 10^{-11}\left(\mathbf{8 5}, \mathrm{R}_{\mathrm{F}}=\mathrm{CF}_{3}\right)$ and $6.6 \cdot 10^{-11}\left(\mathbf{8 5}, \mathrm{R}_{\mathrm{F}}=\mathrm{C}_{5} \mathrm{~F}_{11}\right)$, whereas compound $86\left(\mathrm{R}_{\mathrm{F}}=\mathrm{C}_{3} \mathrm{~F}_{7}\right)$ has $\mathrm{K}_{\mathrm{b}}=1.74 \cdot 10^{-11}$.

$$
\mathrm{R}_{\mathrm{F}} \mathrm{C}\left(\mathrm{NH}_{2}\right)=\mathrm{NN}\left(\mathrm{CH}_{3}\right)_{2}
$$

85

$$
\mathrm{R}_{\mathrm{F}} \mathrm{C}\left(\mathrm{NH}_{2}\right)=\mathrm{NNH}_{2}
$$

86

5.1.2 Tautomerism. Amidrazones are divided into two classes: those able to exhibit tautomerism between $N^{2}$ and $N^{3}$ and those unable to exhibit this phenomenon. Although amidines of the type $\mathbf{8 7}$ have been reported to have been isolated in two distinct forms (87a and 87b), presumably due to the presence of the sulfonyl groups, ${ }^{80}$ no substantiated claims for the isolation of any two tautomers of an amidrazone are known; the earlier claims of von Pechmann ${ }^{39}$ have been proved false. 


$$
\begin{array}{cc}
\mathrm{C}_{6} \mathrm{H}_{5} \mathrm{C}\left(=\mathrm{NSO}_{2} \mathrm{R}\right) \mathrm{NH}_{2} & \mathrm{C}_{6} \mathrm{H}_{5} \mathrm{C}(=\mathbf{\text { 87 }}
\end{array}
$$

5.1.3 Spectral properties. The IR spectra for perfluoroalkylamidrazones showed three mediumstrong bands in the 3500-3100 $\mathrm{cm}^{-1}$ region due to $\mathrm{NH}_{2}$ and $\mathrm{NH}$ stretch. Two other strong bands in the $1700-1600 \mathrm{~cm}^{-1}$ region were assigned to $\mathrm{C}=\mathrm{N}$ stretch $\left(1690 \mathrm{~cm}^{-1}\right)$ and $\mathrm{NH}_{2}$ deformation $\left(1655 \mathrm{~cm}^{-1}\right)$. A weak band due to $\mathrm{NH}$ deformation was also noticed around $1690 \mathrm{~cm}^{-1}$. The $N^{l}, N^{l}$-dialkyl compounds also gave two bands in the region $3550-3380 \mathrm{~cm}^{-1}$ as well as the 1670 and $1655 \mathrm{~cm}^{-1}$ bands. $N^{3}$-Arylamidrazones of the type $\operatorname{ArC}\left(=\mathrm{NNH}_{2}\right) \mathrm{NHAr}$ have also been found to exhibit bands at 3427 and $3300 \mathrm{~cm}^{-1}$, indicating interaction between the $\mathrm{NH}_{2}$ and $\mathrm{NH}$ vibrations. ${ }^{81}$

$$
o-\mathrm{RC}_{6} \mathrm{H}_{4} \mathrm{CH}(\mathrm{OH}) \mathrm{C}\left(\mathrm{NH}_{2}\right) \stackrel{+}{\mathrm{NHNHC}}{ }_{6} \mathrm{H}_{5} \mathrm{X}^{-}
$$

88

Optical rotatory dispersion measurements on the compounds $\mathbf{8 8}\left(\mathrm{R}=\mathrm{H}\right.$ or $\left.\mathrm{CH}_{2} \mathrm{O}, \mathrm{X}=\mathrm{Cl}\right)$ gave plain curves down to $285 \mathrm{~m} \mu$ at which point light absorption proved too great for further examination. ${ }^{82}$ However, the (+)-amidrazone $(-)$-mandelate $\left(\mathbf{8 8}, \quad \mathrm{R}=\mathrm{CH}_{2} \mathrm{O} ; \mathrm{X}=\right.$ $\left.\mathrm{C}_{6} \mathrm{H}_{5} \mathrm{CH}(\mathrm{OH}) \mathrm{COO}\right)$ exhibited a Cotton effect curve of high amplitude $(+4260$ peak $283 \mathrm{m \mu}$; 7390 trough, $263 \mathrm{~m} \mu$ ), due probably to the presence of the various aromatic chromophores. ${ }^{82}$ The optically active amidrazone $\mathbf{8 8}(\mathrm{R}=\mathrm{H})$ and its hydrochloride have been prepared by interaction of phenylhydrazine with ethyl (-) mandelimidate hydrochloride. ${ }^{83} N^{l}$-Phenylmethoxymandelamidrazone has been resolved by means of the mandelic acids.

\subsection{Methods in the synthesis of amidrazones}

\subsubsection{Interaction of nitriles with hydrazines}

5.2.1.1 Hydrazine. Nucleophilic attack of hydrazine on a cyanamide can lead to amidrazone (Scheme 45). ${ }^{84}$

$$
\mathrm{H}_{2} \mathrm{NCN}+\mathrm{NH}_{2} \mathrm{NH}_{2} \longrightarrow \mathrm{H}_{2} \mathrm{~N} \longrightarrow \mathrm{NH}_{2}^{\mathrm{NNH}_{2}}
$$

\section{Scheme 45}

5.2.1.2 Monosubstituted hydrazines. It was also shown that the reaction between phenylhydrazine and cyanogen can give rise to two products (Scheme 46). ${ }^{85}$ 


$$
(\mathrm{CN})_{2}+\mathrm{C}_{6} \mathrm{H}_{5} \mathrm{NHNH}_{2} \longrightarrow \mathrm{NC}-(\underbrace{\mathrm{NNHC}_{6} \mathrm{H}_{5}}_{\mathrm{NH}_{2}}+(\underbrace{\mathrm{NNHC}_{6} \mathrm{H}_{5}}_{2})
$$

\section{Scheme 46}

5.2.1.3 Disubstituted hydrazines. Herbicides of the general formula $\left(\mathrm{CH}_{3}\right)_{2} \mathrm{NN}=\mathrm{C}\left(\mathrm{NH}_{2}\right)$ $\mathrm{C}\left(\mathrm{NH}_{2}\right)=\mathrm{NNH}_{2}$ have been synthesized in a two step processes. ${ }^{78}$ The first step involves the reaction of the cyanogen with dimethylhydrazine in hexane at $5{ }^{\circ} \mathrm{C}$ (Scheme 47). The second contains treatment of the resultant cyanoformamidrazone at higher temperatures with hydrazine in isopropyl alcohol (Scheme 47).<smiles>CN(C)C(N)=NC(N)=NN(C)C(=N)N</smiles>

\section{Scheme 47}

5.2.2 Interaction of nitriles with hydrazines. A modification of the general procedure consists in the introduction of sodium into the reaction. Thus methylphenylhydrazine and benzonitrile in benzene were condensed in the presence of sodium to produce $N^{l}$-methylphenylbenzamidrazone (Scheme 48). ${ }^{86}$

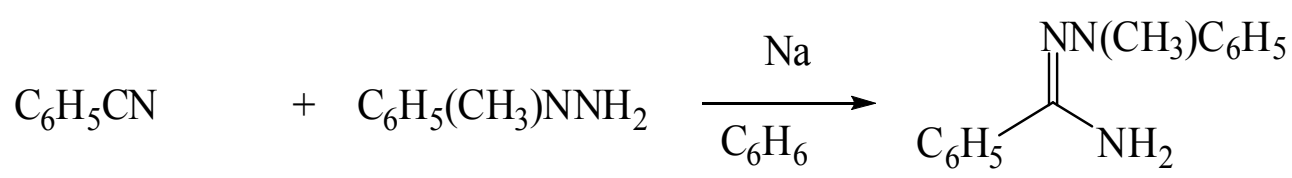

\section{Scheme 48}

\subsubsection{From imidates and their salts}

5.2.3.1 Monosubstituted hydrazines. Imidate salts react smoothly in alcohol at room temperatures with monosubstituted hydrazines. The products are mainly $N^{l}$-substituted amidrazones, but in some cases formazans; such as, dihydroformazan, may form in these reactions. When two parts of hydrazine to one part of imidate are employed, the corresponding formazans are obtained in good yield (Scheme 49). ${ }^{86-89}$ 


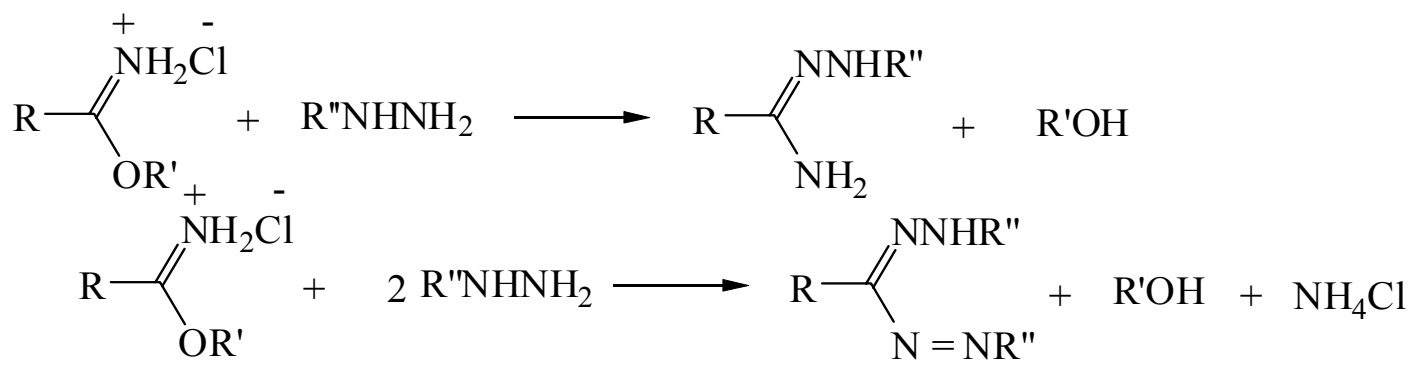

\section{Scheme 49}

5.2.4 From hydrazonoyl halides by aminolysis. Halogenation of benzaldehyde phenylhydrazones with bromine occurs both in the $\omega$-position and in the $N$-phenyl group. The $\omega$ brominated product is very reactive and reacts with concentrated aqueous ammonia solutions to give amidrazones (Scheme 50). ${ }^{90}$

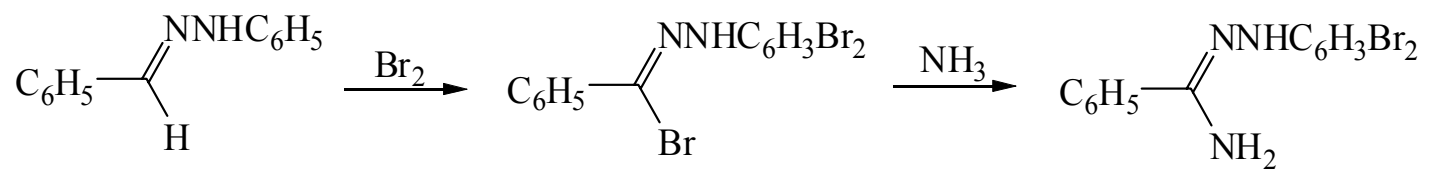

\section{Scheme 50}

5.2.5 From imidoyl halides with hydrazines or acid hydrazides. This process is base on the reaction of an imidoyl halide with a substituted hydrazine. ${ }^{91}$ This reaction can give rise to two products if suitably chosen monosubstituted hydrazines are used. These products are the $N^{1}, N^{3}$ and the $N^{2}, N^{3}$-disubstituted amidrazones (Scheme 51).<smiles>ClC(=Nc1ccccc1)c1ccccc1</smiles>

\section{Scheme 51}

5.2.6 From of other imidic acid derivatives with hydrazines. $N, N^{\prime}$-Disubstituted amidines react with phenylhydrazine at temperatures around $100{ }^{\circ} \mathrm{C}$ to give $N^{l}, N^{3}$-disubstituted amidrazones (Scheme 52). ${ }^{92}$

\section{Scheme 52}

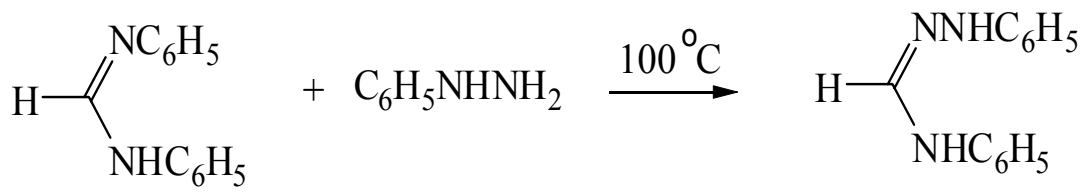




\subsubsection{From amides and thioamides}

5.2.7.1 Amides. Amides provide a feasible starting point to the synthesis of amidrazones, either directly or via the imidoyl halide. A typical example of a direct synthesis is the condensation of an $\mathrm{N}, \mathrm{N}$-disubstituted amide with a substituted hydrazine in the presence of phosphorus oxychloride (Scheme 53). ${ }^{38,93-95}$

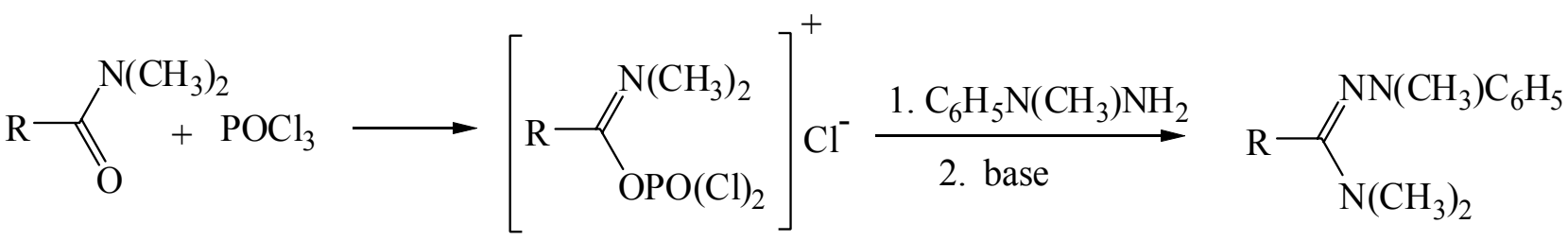

\section{Scheme 53}

5.2.7.2 Thioamides. Cyanothioamides react with hydrazines to give amidrazones among other products. ${ }^{96}$ Thus various oxalic acid derivatives have been prepared in this way using $\mathrm{NCCSNH}_{2}, \mathrm{H}_{2} \mathrm{NCSCSNH}_{2}, \mathrm{C}_{2} \mathrm{H}_{5} \mathrm{OOCCSNH}_{2}$, and $\mathrm{HOOCCSNH}_{2}$ as starting materials (Scheme $54) .{ }^{97}$

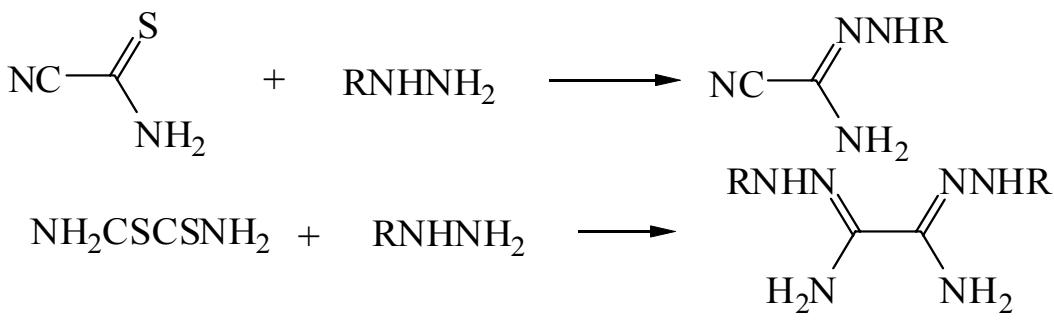

Scheme 54

5.2.8 Reduction of nitrazones. Treatment of $N$ - $m$-nitrophenylacetnitrazone with tin dichloride in hydrochloric acid afforded the reduced $N^{l}$-( $m$-aminophenyl)acetamidrazone; however, it failed to produce any amidrazone (Scheme 55$).{ }^{98}$

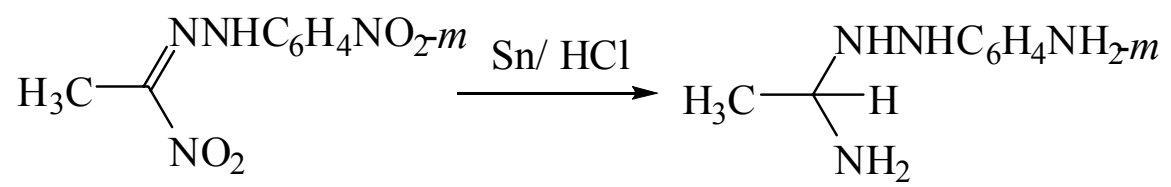

\section{Scheme 55}

5.2.9 Reduction of formazans and tetrazolium salts. The stepwise hydrogenation of tetrazolium salts and formazans has been studied (Scheme 56). ${ }^{99,100}$ The successful methods of 
reduction are (a) hydrogenation using 5\% palladium on barium sulfate, (b) Raney nickel in methanol and (c) the use of sodium dithionite. The reduction process follows the sequence as outlined in Scheme 56. ${ }^{99,100}$

\section{Scheme 56}

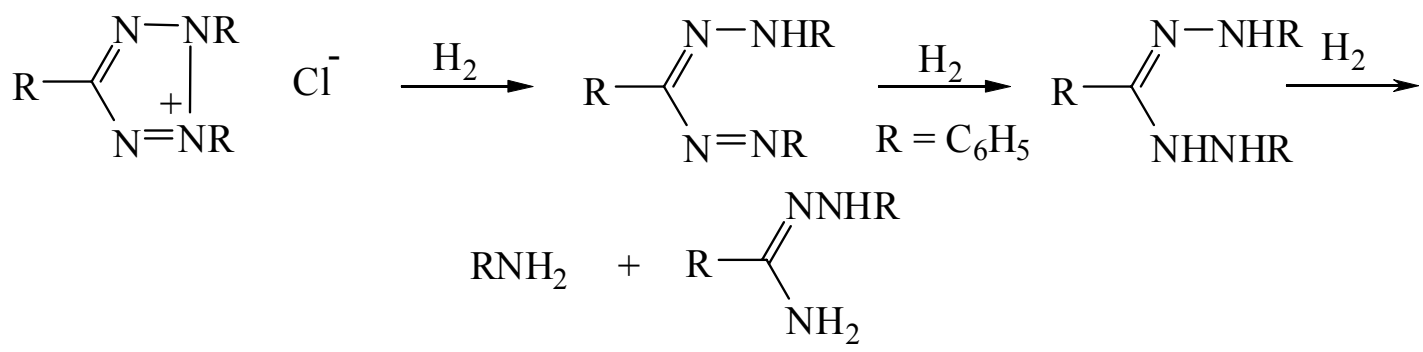

5.2.10 From heterocyclic systems. In addition to the tetrazolium salts, various heterocyclic systems have been used to prepare amidrazones through interaction with hydrazines, although the heterocyclic precursors themselves are not always easily formed. Thus the reaction of 1,3,4oxathiazoline 3-dioxide in dioxane solution with hydrazine gives good yields of amidrazones (Scheme 57). ${ }^{101}$

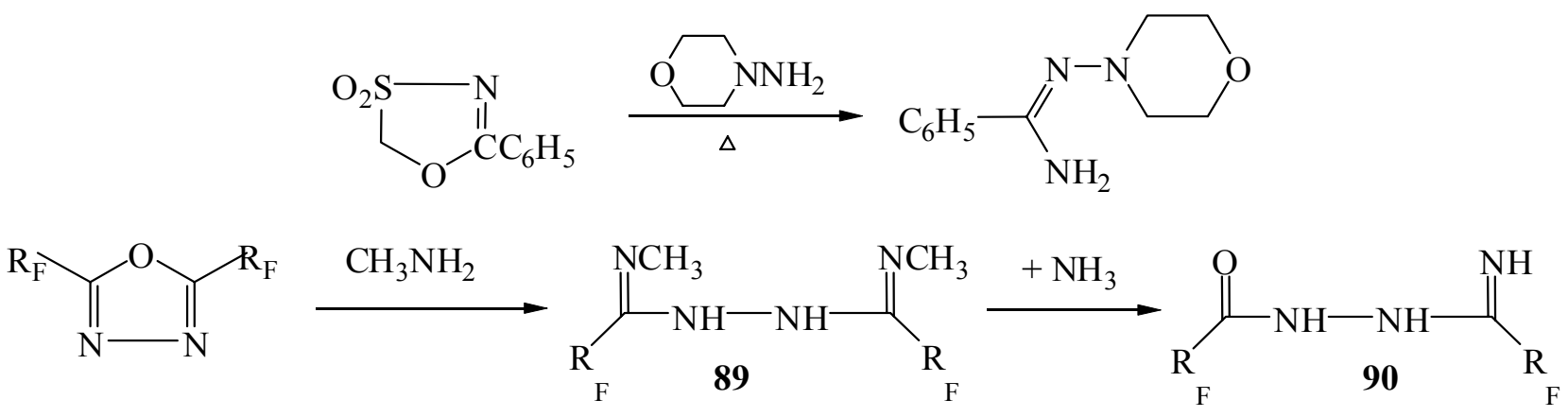

\section{Scheme 57}

2,6-Bis(perfluoroalkyl)-1,3,4-oxadiazoles readily underwent nucleophilic attack at a ring carbon atom to give products of the type 89, ${ }^{102}$ which reacted with ammonia to give compounds of formula 90 (Scheme 57).

5.2.11. From ketimines, acetylenes, and carbodiimides. Addition of hydrazine to a ketimine of type 91 produced $N^{l}$-substituted amidrazones (Scheme 58). ${ }^{103}$

$$
\left(\mathrm{C}_{6} \mathrm{H}_{5}\right)_{2} \mathrm{C}=\underset{\mathbf{9 1}}{\mathrm{C}=\mathrm{NC}_{6} \mathrm{H}_{4} \mathrm{CH}_{3} \stackrel{\mathrm{NH}_{2} \mathrm{NH}_{2}}{\longrightarrow}} \stackrel{\left(\mathrm{C}_{6} \mathrm{H}_{5}\right)_{2} \mathrm{CH} \longrightarrow \mathrm{NHC}_{6} \mathrm{H}_{4} \mathrm{CH}_{3}}{\mathrm{NNH}_{2}}
$$

\section{Scheme 58}




\subsection{Reactions of amidrazones}

5.3.1 Reaction with Grignard reagents. The formyl group of $N^{l}$-formylformamidrazones (e.g. 92) reacts with phenylmagnesium bromide to afford benzaldehyde and a small amount of benzhydrol. $N^{3}, N^{3}$-Dimethyl- $N^{1}$-phenyl-formamidrazone was found to give only a trace of benzaldehyde on treatment with the Grignard reagent (Scheme 59). ${ }^{104}$

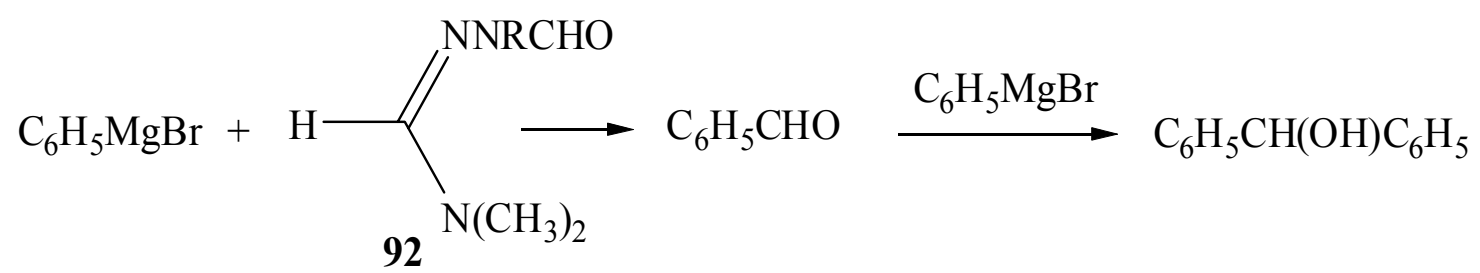

\section{Scheme 59}

\subsubsection{Action of nitrous acid on amidrazones}

5.3.2.1 Monosubstituted amidrazones. Although $N^{l}$-substituted amidrazones cannot form imideazides, they nevertheless form 2,5-disubstituted tetrazoles on treatment with nitrous acid (Scheme 60). ${ }^{105}$<smiles>N=C(NO)c1ccccc1</smiles>
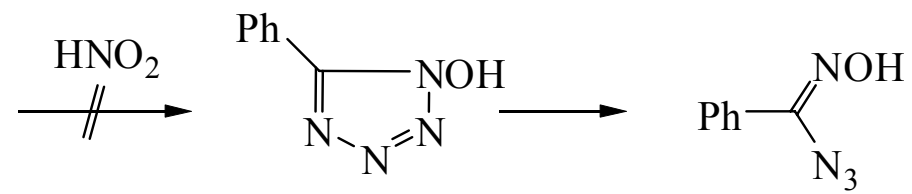

\section{Scheme 60}

\subsubsection{Condensation of amidrazones with aldehydes or ketones}

5.3.3.1 Unsubstituted amidrazones. $p$-Toluamidrazone gave compound 93 on treatment with benzaldehyde. Aminoguanidine reacts in similar reaction with aldehydes (Scheme 61). ${ }^{106}$ Bladin ${ }^{107}$ obtained two products from the action of excess benzaldehyde with an alcoholic solution of $N^{l}$-phenylcyanoformamidrazone, namely a Schiff base 94 and a triazole 95 (Scheme 62).<smiles>Cc1ccccc1C(N)=NC(=N)Cc1ccccc1</smiles>

Scheme 61 
<smiles>N#CC(N)=Nc1ccccc1</smiles>

\section{Scheme 62}

5.3.4 Synthesis of 1,2,4-triazines. $N$-Unsubstituted amidrazones condense only with dicarbonyl compounds to yield 1,2,4-triazines (Scheme 63). ${ }^{108}$

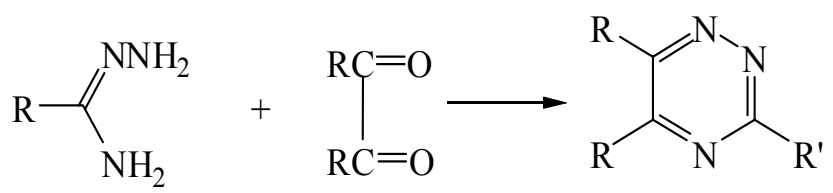

\section{Scheme 63}

\subsubsection{Miscellaneous heterocyclic systems}

5.3.5.1 Bisoxadiazoles. The reaction ${ }^{109}$ of carbon disulfide with amidrazones produced the corresponding 2-thioxo-thiadiazoles, whereas the cyclization of the oxalamidrazone ${ }^{110}$ at $100{ }^{\circ} \mathrm{C}$ in dichloroacetic acid gave the corresponding bisoxadiazolyl (Scheme 64).

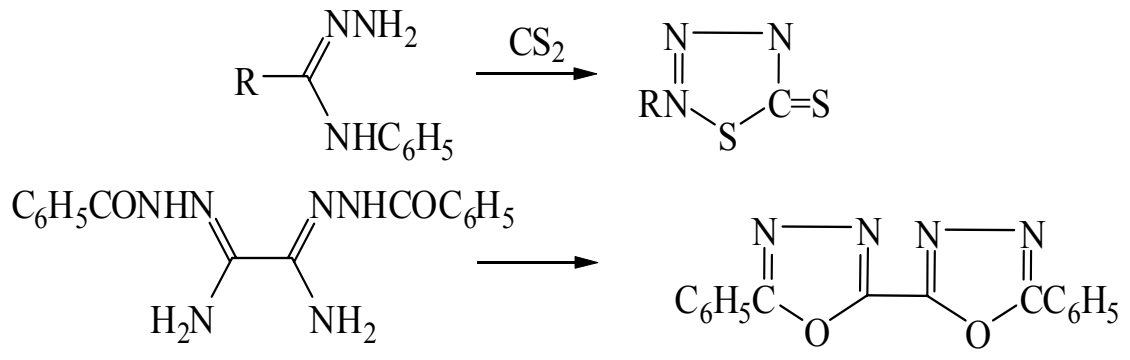

\section{Scheme 64}

5.3.5.2 Benzimidazole. It was reported that 1,1,1-trimethyl-2-benzoylhydrazinium hydroxide $(96)^{111}$ reacted with phenyl isocyanate via salt 97 formation, which on extrusion of $\mathrm{CO}_{2}$ produced 98 . Heating 98 yielded the corresponding $1 H$-benzimidazole (99) (Scheme 65). ${ }^{111}$ 


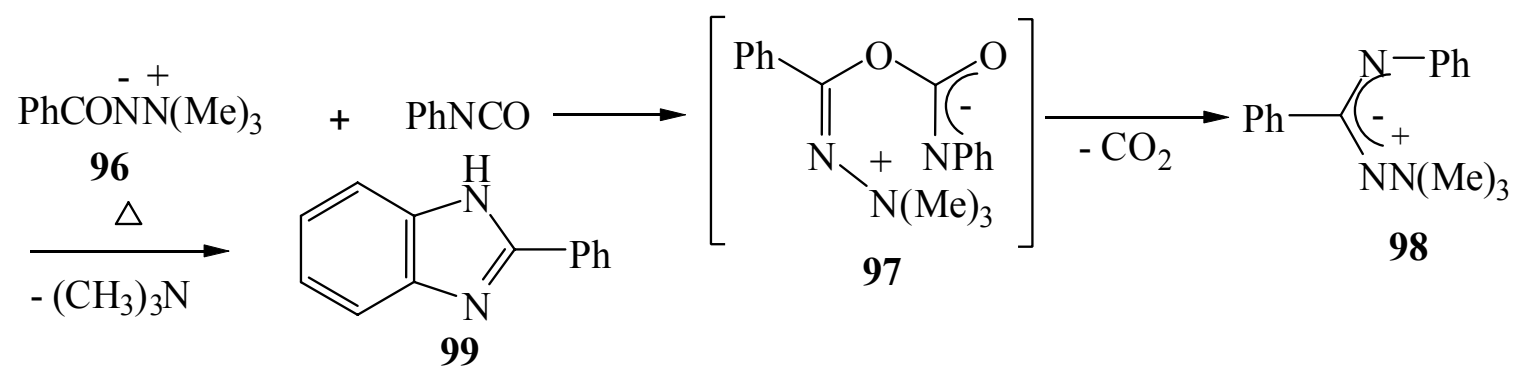

\section{Scheme 65}

Aly et al. reported the syntheses of various classes of 1,2,4-triazoles $\mathbf{1 0 0}$ from the reaction of amidrazones with 2-dicyanomethyleneindane-1,3-dione (CNIND, 56) (Scheme 66). ${ }^{112}$<smiles>[R]c1ccc(C(=N)c2ccccc2)c([R])c1[R]</smiles><smiles>N#CC(C#N)=C1C(=O)c2ccccc2C1=O</smiles>

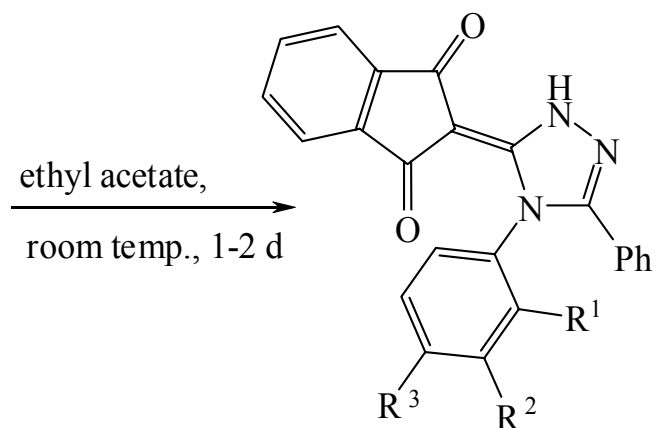

$100(70-85 \%)$

\section{Scheme 66}

5.3.5.3 Bis(indole)pyrazinone. The preparation of unsubstituted indole-amidrazones turned out to be relatively straightforward (Scheme 67). Beginning from commercially available $1 H$-indole (31), in three steps, the desired amidrazone $\mathbf{1 0 2}$ was obtained in good yield, via formation of indolyl-3-carbonitrile 101 (Scheme 67). ${ }^{113-115}$ In the cyclocondensation reaction, exposure of amidrazone 103 to ketoester $104^{116}$ in the presence of $\mathrm{MgSO}_{4}$ in methanol, followed by reflux in DMF, afforded the desired anti-triazinone product $\mathbf{1 0 5}$ in 68\% yield (Scheme 68) in addition to syn-triazinone 106 as a minor product ${ }^{116}$<smiles>c1ccc2[nH]ccc2c1</smiles>

31<smiles>N#Cc1c(-c2ccccc2)[nH]c2ccccc12</smiles>

101<smiles>N/N=C(\N)c1c[nH]c2ccccc12</smiles>

\section{Scheme 67}




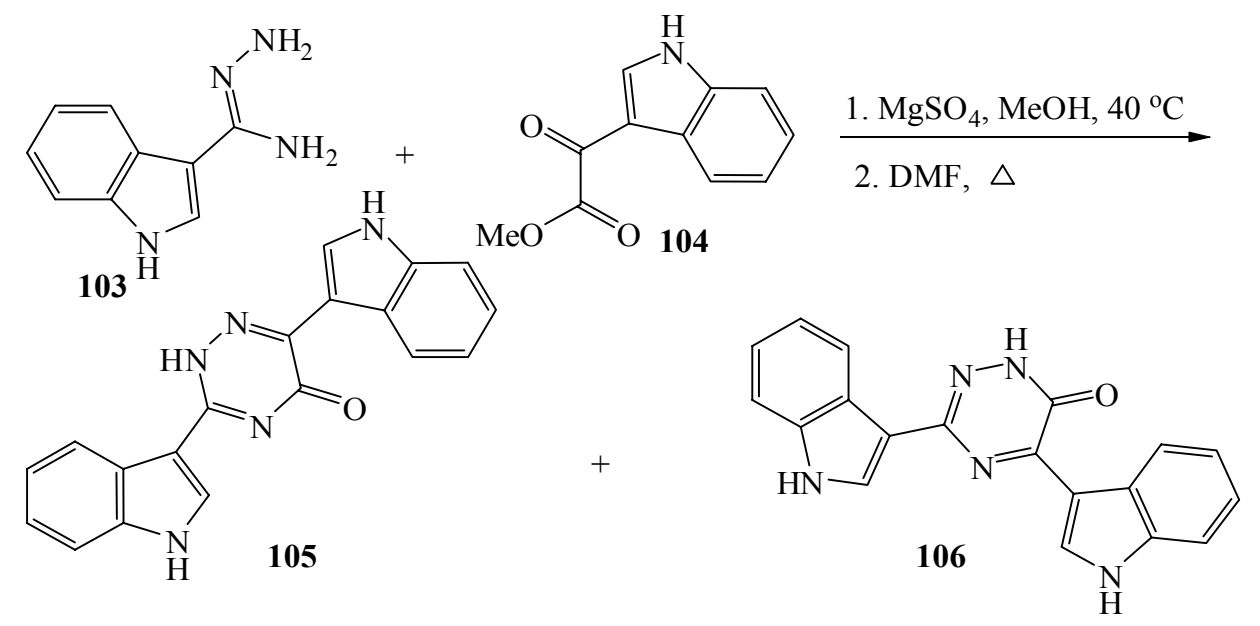

\section{Scheme 68}

5.3.5.4 Pyrazolo[3,4-d]pyrimidines. The imidoesters 108 were obtained by coupling 5-amino1H-pyrazole-4-carbonitriles 107 with triethyl orthoformate (Scheme 69). ${ }^{17-121}$

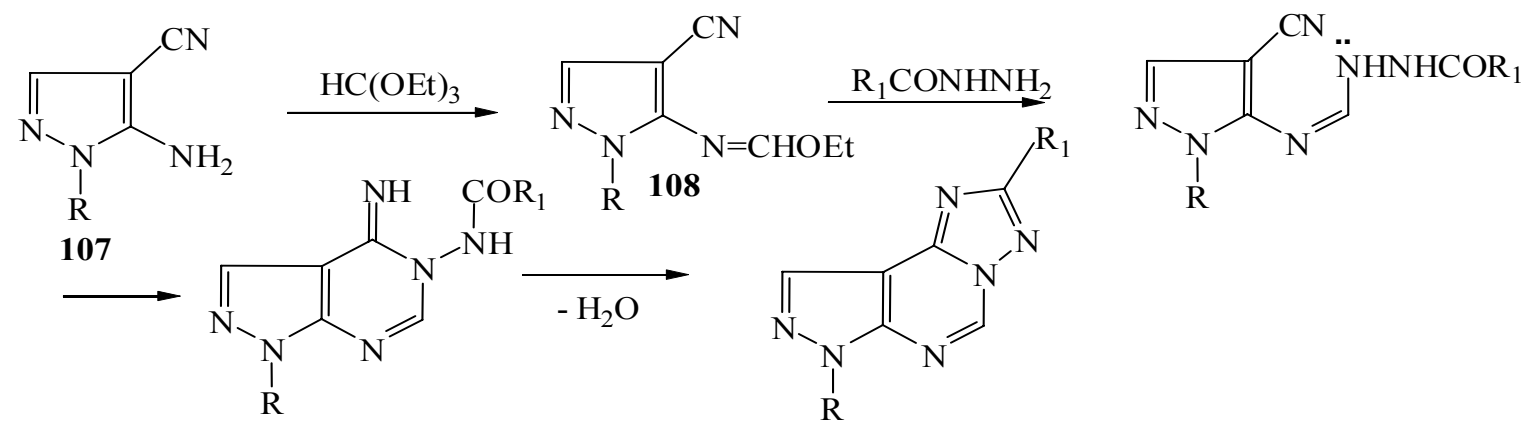

\section{Scheme 69}

5.3.5.5 Pyrazolo[1,5-c]pyrimidines. The substituted amidrazones react with triphenylpyrylium to give pyridinium salts which can be converted to carbodimides. ${ }^{122}$ In the presence of $\mathrm{NEt}_{3} / \mathrm{HOAc}$, the reaction takes a different course and bicyclic products $\mathbf{1 0 9}$ are formed (Scheme 70). 


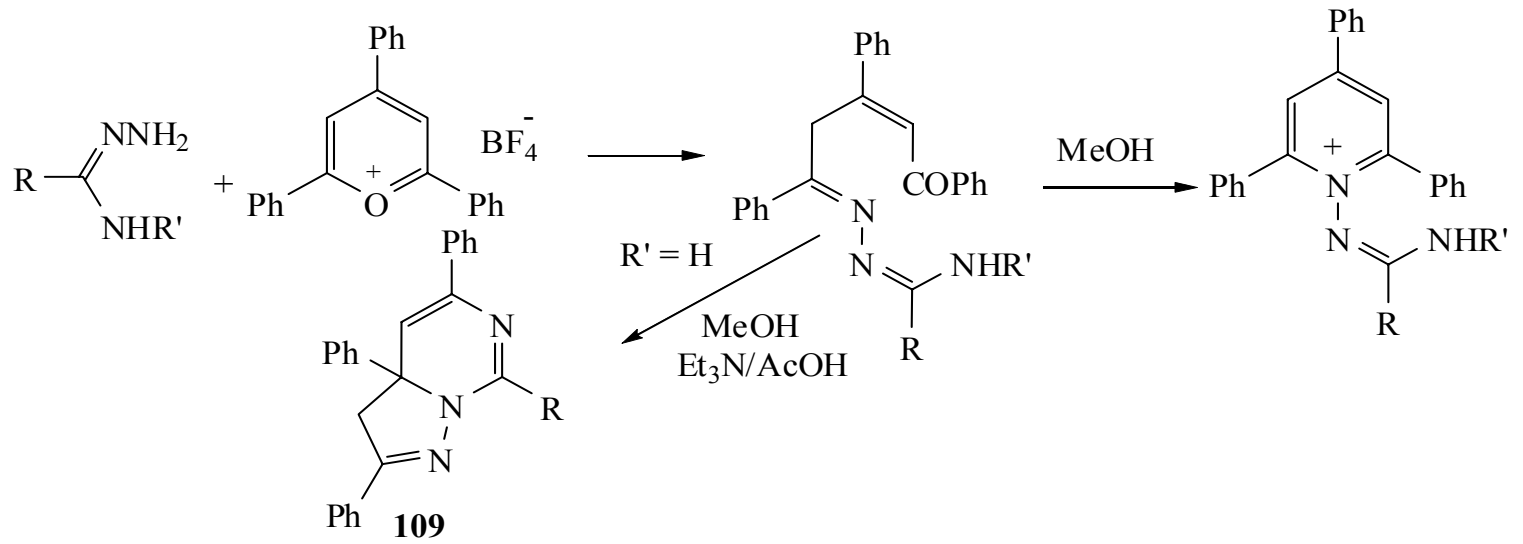

\section{Scheme 70}

5.3.5.6 1,2,4-Triazoles. Amidrazones are considered as precursors for preparing various triazoles $($ Scheme 71$) .{ }^{123-127}$

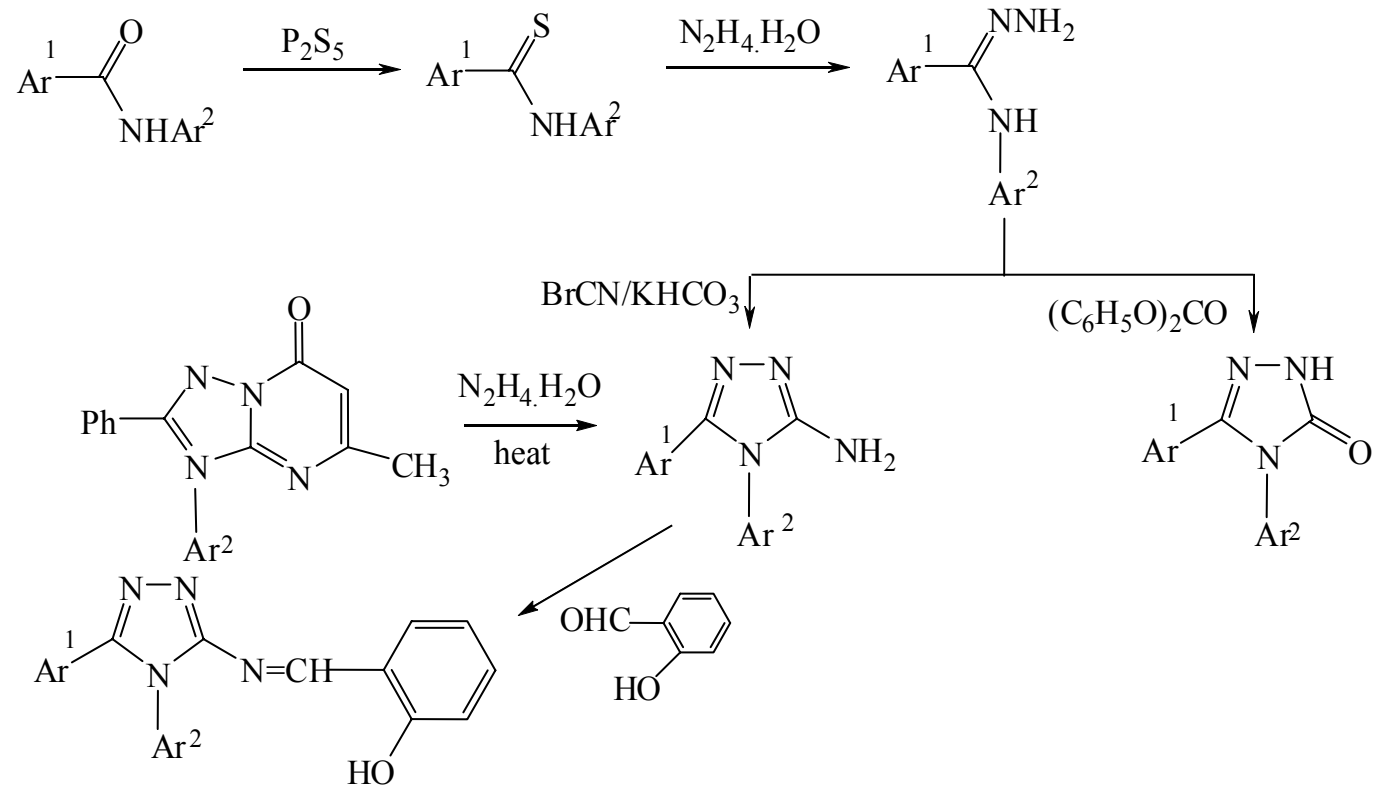

\section{Scheme 71}

5.3.5.7 1,2,4-Triazines. The reaction of the $N^{3}$-substituted amidrazones with dimethyl acetylenedicarboxylate (DMAD, 72) in absolute ethanol at the temperature of $-10{ }^{\circ} \mathrm{C}$ led to the formation of derivatives of dimethyl 2-[(1-aryl-amino-1-arylmethylidene)hydrazono]succinates 110. ${ }^{128,129}$ Cyclization of $\mathbf{1 1 0}$ was carried out in methanol solution in the presence of triethylamine and led to the formation of methyl 2-(5-oxo-3,4-diaryl-1,4,5,6-tetrahydro-1,2,4triazine-6-ylidene)acetates $\mathbf{1 1 1}$ as shown in Scheme 72. 
<smiles>[R]C[R]C([R])=N/N=C(\CC(=O)OC)C(=O)OC</smiles>

\section{Scheme 72}

Aly et al. have recently reported the synthesis of fused triazines, benzoindazoles, 1,2,4triazepine-6,11-diones and hydrazino-butane-1,4-diones. These products were obtained in the reaction of amidrazones with $\pi$-deficient compounds. As it is outlined in Scheme 73, amidrazones reacted with two equivalents of 1,4-quinone (112) or 1,4-naphthoquinone (114) to give, in a few minutes, after chromatographic purification and recystallization, compounds 113 (66-85\%) and $115(70-86 \%)$, respectively (Scheme 73). ${ }^{130}$ In a different manner, the reactions of amidrazones with 2,3,5,6-tetrachloro-1,4-benzoquinone (116) and 2,3-dichloro-1,4naphthoquinone (119) (Scheme 74) in dry DMF produced single product for all substituted amidrazones (Scheme 74). ${ }^{130}$ The reaction mechanism can be described as due to formation of intermediate like 117 (Scheme 74). Syntheses of various 4-aryl-5-imino-3-phenyl-1Hnaphtho[2,3-f]-1,2,4-triazepine-6,11-diones 122 are reported by Aly et al. Their successful synthesis depends on the reaction of amidrazones with 1,4-dioxo-1,4-dihydronaphthalene-2,3dicarbonitrile (121, Scheme 75). ${ }^{131}$ Various 1,4-diphenyl-2-arylamino-2-\{[1-phenyl-meth-(Z)ylidene]-hydrazino\}-butane-1,4-diones 124 were obtained by the reaction of amidrazones with 1,4-diphenyl-2-butyne-1,4-dione (123) in boiling ethanol (Scheme 76). ${ }^{132}$<smiles>O=c1cc2c3ccccc3c-2nnc(-c2ccccc2)n1[Al]</smiles>

$115(70-86 \%)$

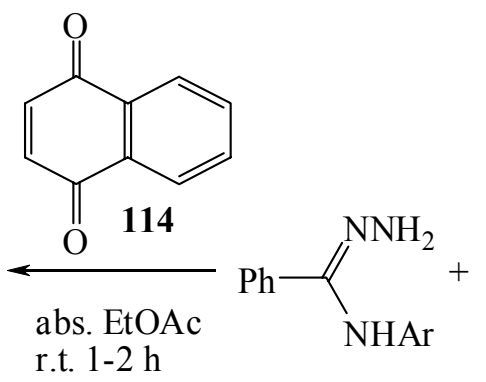

r.t. 1-2 h

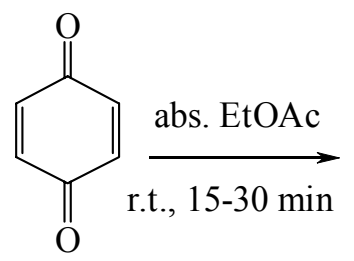

112<smiles>O=c1ccc2nnc(-c3ccccc3)n([Al])c-2c1</smiles>

$113(66-85 \%)$

\section{Scheme 73}




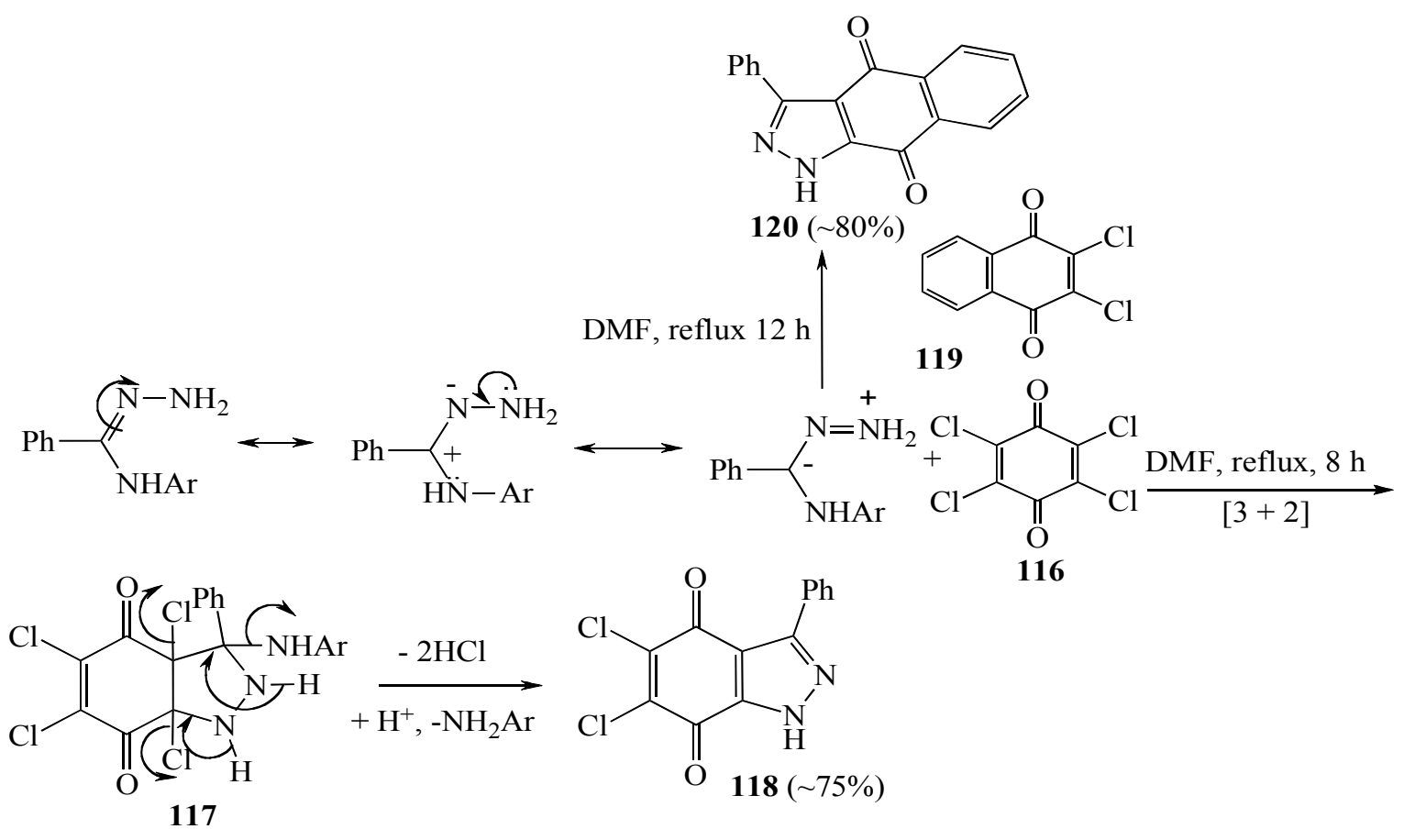

\section{Scheme 74}<smiles>[R]c1ccc(NC(=N)c2ccccc2)cc1[R]</smiles>

ne 75<smiles>N#CC1=C(C#N)C(=O)c2ccccc2C1=O</smiles>

abs. Ethyl acetate

r.t. $10-30 \mathrm{~min}$<smiles>[R]c1ccc(-n2c(-c3ccccc3)n[nH]c3c(=O)c4ccccc4c(=O)c=3c2=N)cc1[R]</smiles>

\section{Scheme 75}

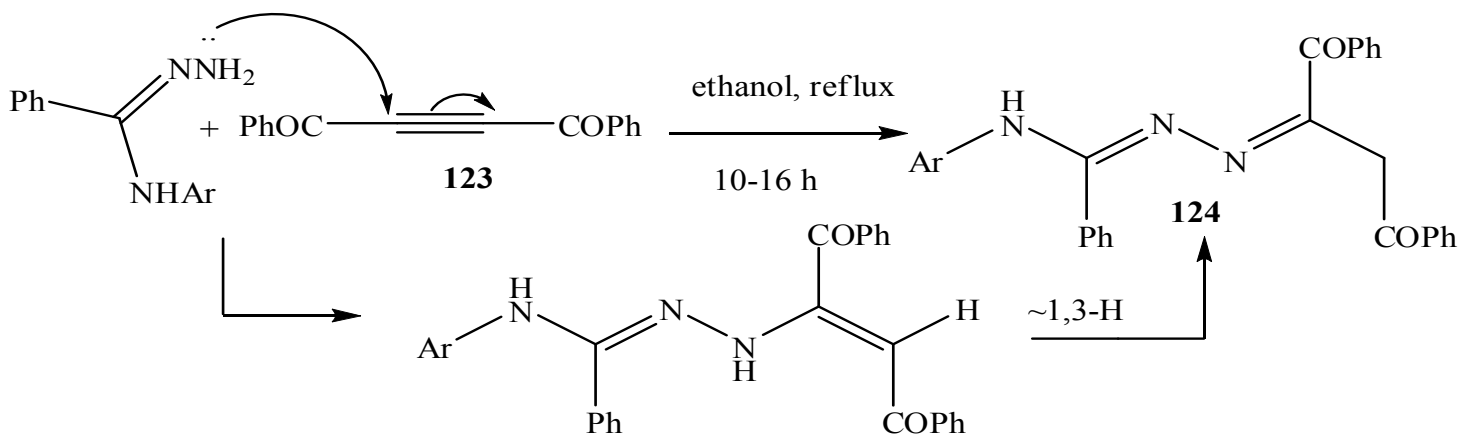

\section{Scheme 76}




\section{Reaction of Monosaccharides with 2-Pyridylcarboxamidrazone}

2-Pyridylcarboxamidrazone and its heterocyclic derivatives showed antimicrobacterial activity ${ }^{133}$ and anticancer activity. ${ }^{134}$ The phenylalanine derivative (S)-3-(4-amidrazonophenyl)- $N$ cyclopentyl- $N$-methyl-2-(naphthalene-2-sulfonyl)propionamide (LB30057) was identified as potent selective and orally active thrombin inhibitor; several derivatives had also significant enhancing potency as thrombin inhibitors. ${ }^{135}$ Carbohydrates have attracted much attention as starting material in organic synthesis. ${ }^{136}$ The application of hydrazones ${ }^{137}$ derived from carbohydrates for the synthesis of heterocycles ${ }^{137}$ and acyclic (seco)-nucleosides has been reported. ${ }^{138}$ Moreover, the reaction of sugars with 2-pyridylhydrazine has been investigated. ${ }^{139-}$ ${ }^{141}$ The reactions of the close analogue, 2-pyridylcarboxamidrazone with $D$-arabinose (125) along with $D$-xylose (126) have been studied and products 127 and 128 were obtained (Scheme 77).

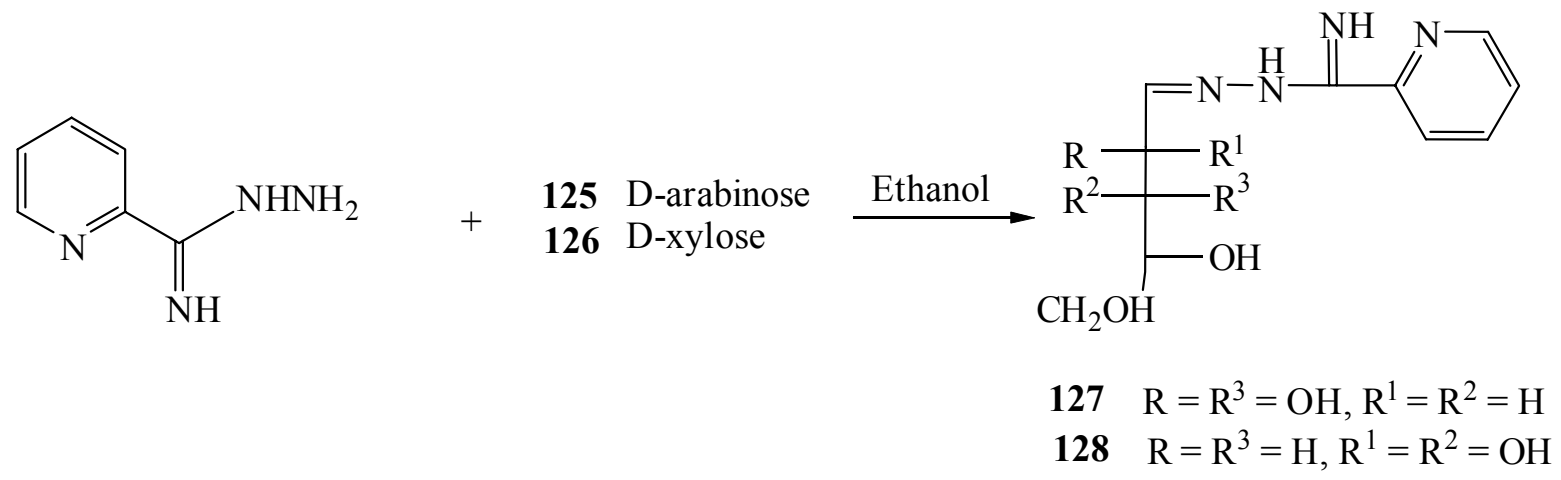

\section{Scheme 77}

\section{Industrial and Medicinal Applications of Amidrazones}

A process has been described for obtaining thermally stable polymers containing amidrazones and/or 1,2,4-triazoles from, e.g., isophthalaldehyde and hexafluoroglutaramidrazone. ${ }^{142} \mathrm{~A}$ further patent describes the use of amidrazones, e.g., from heptafluorobutyronitrile and hydrazine, as intermediates in the synthesis of 2-perfluoroalkyl-5-aryl-1,3,4-triazoles which are useful as heattransfer media. ${ }^{143,144}$ Amidrazones and triazoles of the anthraquinone series have been described and used in the production of vat dyes; these include compounds of the types $\mathbf{1 2 9}$ and $\mathbf{1 3 0}$ in which R, R', and R" are all aromatic groups of which at least one is an anthraquinone residue. ${ }^{144-}$ 148 


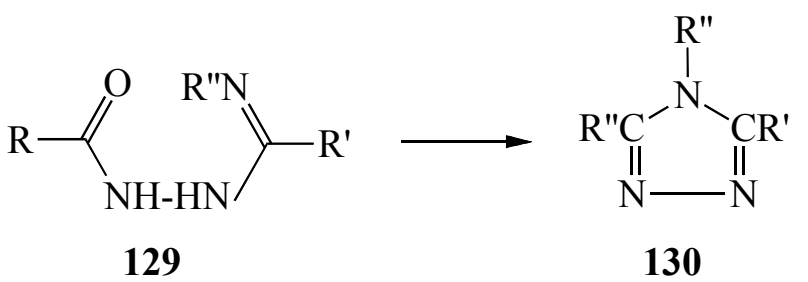

Aminoguanidine is an important precursor for many useful compounds, ${ }^{149}$ among them the plant growth regulator, 3-amino-1,2,4-triazole. ${ }^{150}$ Amidrazones derived from nicotinic and isonicotinic acids among others have been tested for their pharmacological activity. ${ }^{151,152}$ Pyridine-4-carboxamidrazone is reported to be about half as effective as isoniazid in its tuberculostatic properties but only about one-half to one-third as toxic. Moreover, the isonicotinamidrazone-rifamycin- $O$ reaction product has been found to be very active against

gram positive microorganisms. ${ }^{153,154}$ Pteridine amidrazone or their aldehyde or ketone condensation products have been the subject of several patents as compounds that have diuretic and natiuretic properties. ${ }^{155}$

\section{References}

1. Patai, S., Ed. The Chemistry of Carboxylic Acids and Esters; Interscience: London, 1969.

2. Patai, S., Ed. The Chemistry of the Carbon-Nitrogen Double Bond; Interscience: London, 1970.

3. Zabicky, J., Ed. The Chemistry of Amides; Interscience: London, 1972.

4. Kotera, A.; Morita, T.; Aoyagi, S.; Kakiuchi, Y.; Nagakura, S.; Kume, K.. Nippon Kagaku Zasshi, 1961, 82, 298; Chem. Abstr. 1961, 55, 15128e.

5. Kiro, Z. B.; Teterin, Yu. A.; Nikolenko, L. N.; Stepanov, B. I. Zh. Org. Khim. 1972, 8, 2573; Chem. Abstr. 1973, 78, 135210z.

6. Hantzsch, A.; Geidel, W. Ber. Dtsch. Chem. Ges. 1930, 63, 1782.

7. Runner, M. E.; Kilpatrick, M. L.; Wagner, E. C. J. Am. Chem. Soc. 1947, 69, 1406.

8. Neuman, R. C., Jr.; Hammond, G. S. J. Phys. Chem. 1963, 67, 1659.

9. (a) Gauter, J. A.; Miocque, M.; Farnoux, C. C. In The Chemistry of Amidines and Imidates, Vol. 1; Patai, S., Ed.; John Wiley \& Sons: New York, 1975, p 283. (b) Boyd, G. V. In The Chemistry of Amidines and Imidates, Vol. 2; Patai, S., Rappoport, Z., Eds.; John Wiley \& Sons: New York, 1991, p 367. (c) Granik, V. G. Russ. Chem. Rev. 1983, 52, 377. (d) Dunn, P. J. In Comprehensive Organic Functional Group Transformations; Katritzky, A. R.; MethCohn, O.; Rees, C. W.; Eds.; Pergamon: New York, 1995, Vol. 5, Chapter 5.19.

10. (a) Partridge, M. W.; Smith, A. J. Chem. Soc., Perkin Trans. 1 1973, 453. (b) Hill, A. J.; Johnston, J. V. J. Am. Chem. Soc. 1954, 76, 920. (c) Tsatsas, G.; Delaby, R.; Quevauviller, A.; Damiens, R.; Blanpin, O. Ann. Pharm. Fr. 1956, 14, 607. (d) Mandel, H. G.; Hill, A. J. J. Am. Chem. Soc. 1954, 76, 3978.

11. Weintraub, L.; Oles, S. R.; Kalish, N. J. Org. Chem. 1968, 33, 1679. 
12. Kakimoto, M.; Ogata, S.; Mochizuki, A.; Imai, Y. Chem. Lett. 1984, 821.

13. Roger, R.; Neilson, D. G. Chem. Rev. 1961, 61, 179.

14. Schaefer, F. C.; Peters, G. A. J. Org. Chem. 1961, 26, 412.

15. Grivas, J. C.; Taurins, A. Can. J. Chem. 1961, 39, 761.

16. Oxley, P.; Partridge, M. W.; Short, W. F. J. Chem. Soc. 1947, 1110.

17. Garigipati, R. S. Tetrahedron Lett. 1990, 31, 1969.

18. Moss, R. A.; Ma, W.; Merrer, D. C.; Xue, S. Tetrahedron Lett. 1995, 36, 8761.

19. Rousselet, G.; Capdevielle, P.; Maumy, M. Tetrahedron Lett. 1993, 34, 6395.

20. Forsberg, J. H.; Spaziano, V. T.; Balasubramanian, T. M.; Liu, G. K.; Kinsley, S. A.; Duckworth, C. A.; Poteruca, J. J.; Brown, P. S.; Miller, J. L. J. Org. Chem. 1987, 52, 1017.

21. Judkins, B. D.; Allen, D. G.; Cook, T. A.; Evans, B.; Sardharwala, T. E. Synth. Commun. 1996, 26, 4351.

22. Dondoni, A.; Barbaro, G. J. Chem. Soc., Chem. Commun. 1975, 761.

23. Baati, R.; Gouverneur, V.; Mioskowski, C. Synlett 1999, 927.

24. Schnur, R. C. J. Org. Chem. 1979, 44, 3726.

25. Lange, U. E. W.; Schäfer, B.; Baucke, D.; Buschmann, E.; Mack, H. Tetrahedron Lett. 1999, 40, 7067.

26. Nii, Y.; Okano, K.; Kobayashi, S.; Ohno, M. Tetrahedron Lett. 1979, 2517.

27. Dauwe, C.; Buddrus, J. Synthesis 1995, 171.

28. ten Hoeve, W.; Wynberg, H. Synth. Commun. 1994, 24, 2215.

29. Bleriot, Y.; Genre-Grandpierre, A.; Tellier, C. Tetrahedron Lett. 1994, 35, 1867.

30. Moreaux, V.; Warren, H.; Williams, J. M. Tetrahedron Lett. 1997, 38, 4655.

31. Tong, M. K.; Papandreou, G.; Ganem, B. J. Am. Chem. Soc. 1990, 112, 6137.

32. Capdevielle, P.; Maumy, M. Tetrahedron Lett. 1993, 34, 2953.

33. Spychala, J. Tetrahedron Lett. 1999, 40, 2841.

34. Eustache, J.; Grob, A. Tetrahedron Lett. 1995, 36, 2045.

35. Seyferth, D.; Hui, R. C. J. Org. Chem. 1985, 50, 1985.

36. Pinner, A. Die Iminoäther und ihre Derivate, R. Oppenheim: Berlin, 1892.

37. Bernthsen, A. Liebigs Ann. Chem. 1876, 184, 321.

38. von Walther, R.; Grossmann, A. J. Prakt. Chem. 1908, 78, 478; Chem. Zent. 1909, 80(I), 280.

39. von Pechmann, H. Ber. Dtsch. Chem. Ges. 1895, 28, 2362.

40. Lottermoser, A. J. Prakt. Chem. 1896, 54, 113; Chem. Zent. 1896, 67(II), 1054.

41. Müller, H. Ber. Dtsch. Chem. Ges. 1868, 19, 1669.

42. Eloy, F.; Lenaers, R. Chem. Rev. 1962, 62, 155.

43. Graham, W. H. J. Am. Chem. Soc. 1965, 87, 4396.

44. Bose, A. K.; Kugajevsky, I. Tetrahedron 1967, 23, 957.

45. Lorenz, R. R.; Tullar, B. F.; Koelsch, C. F.; Archer, S. J. Org. Chem. 1965, 30, 2531.

46. Hölljes, E. L., Jr.; Wagner, E. C. J. Org. Chem. 1944, 9, 31.

47. Göblyös, A.; De Vries, H.; Brussee, J.; IJzerman, A. P. J. Med. Chem. 2005, 48, 1145. 
48. Zyabrev, V. S.; Rensky, M. A.; Rusanov, E. B.; Drach, B. S. Heteroatom Chem. 2003, 14, 474.

49. Goerdeler, J.; Eggers, W. Chem. Ber. 1986, 119, 3737.

50. L'abbé, G.; Albrecht, E.; Toppet, S. J. Heterocycl. Chem. 1992, 29, 1317.

51. Zyabrev, V. S.; Renskii, M. A.; Drach, B. S. Zh. Org. Khim. 2001, 37, 628.

52. Aly, A. A.; Gomaa, A.-M. M.; Nour-El-Din, A. M.; Fahmi, M. S. Phosphorus, Sulfur, Silicon Relat. Elem. 2008, 138, 1783.

53. Junek, H.; Mittelbach, M.; Thierrichter, B. Monatsh. Chem. 1979, 110, 1279.

54. Snyder, H. R.; Foster, H. M. J. Am. Chem. Soc. 1954, 76, 118.

55. Kenner, G. W.; Lythgoe, B.; Todd, A. R.; Topham, A. J. Chem. Soc. 1943, 388.

56. Schaefer, F. C.; Hechenbleikner, I.; Peters, G. A.; Wystrach, V. P. J. Am. Chem. Soc. 1955, $81,1466$.

57. Grundmann, C.; Schröder, H.; Ruske, W. Chem. Ber. 1954, 87, 1865.

58. Fahey, J. L.; Foster, P. A.; Neilson, D. G.; Watson, K. M.; Brokenshire J. L.; Peters, D. A. V. J. Chem. Soc. C 1970, 719.

59. Titherley, A. W. J. Chem. Soc., Perkin Trans I. 1910, 200.

60. Müller, D.; Beckert, R.; Görls, H. Synthesis 2001, 601.

61. Jackman, L. M.; Jen, T. J. Am. Chem. Soc. 1975, 97, 2811.

62. (a) Wanzlick, H. W.; Schikora, E. Angew. Chem. 1960, 72, 494. (b) Wanzlick, H. W.; Kleiner, H. Angew. Chem. 1961, 73, 493. (c) Wanzlick, H. W.; Schikora, E. Chem. Ber. 1961, 94, 2389.

63. Petzold, C.; Beckert, R.; Günther, W.; Görls, H. Arkivoc 2007, iii, 68.

64. Aly, A. A.; Nour-El-Din A. M.; Gomaa, M. A.-M.; Brown, A. B.; Fahmi, M. S. J. Chem. Res. 2007, 439.

65. Gomaa, M. A.-M.; Döpp, D. Synthesis 2003, 1545.

66. Aly, A. A.; El-Shaieb, K. M. J. Chem. Res. 2007, 207.

67. Aly, A. A.; El-Shaieb, K. M. J. Chem. Res. 2007, 563.

68. Smith, P. A. S. The Chemistry of Open Chain Nitrogen Compounds; W. A. Benjamin: New York, N. Y., 1966; Vol. 2, p 173.

69. Millar, I. T.; Springall, H. D. Sidgwick's Organic Chemistry of Nitrogen, $3^{\text {rd }}$ edn.; Clarendon Press: Oxford, 1966; p 529.

70. IUPAC, Nomenclature of Organic Chemistry, Section C; Butterworth: London, 1965; p 221.

71. Rapoport, H.; Bonner, R. M. J. Am. Chem. Soc., 1950, 72, 2783.

72. Engelhardt, R. J. Prakt. Chem. 1896, 54, 143.

73. (a) Pinner, A. Ber. Dtsch. Chem. Ges. 1884, 17, 182; ibid. 1884, 17, 2002; Liebigs Ann. Chem. 1897, 297, 221. (b) Pinner, A.; Gobel, C.; Salomon, A.; Gradenwitz, F. ibid. 1897, $298,1$.

74. Dedichen, G. Avhandl. Norske Videnskaps-Akad. Oslo, I, Mat.-Naturv. Kl., 1936, 5, 42 pp; Chem. Abstr. 1937, 31, 4985.

75. van der Burg, W. J. Recl. Trav. Chim. Pays-Bas 1955, 74, 257. 
76. Brown, H. C. U.S. Department of Commerce, Office Technical Service, Report A. D. 1961, 257,033 (Chem. Abstr. 1964, 60, 6845h.

77. Ponzio, G. Gazz. Chim. Ital. 1910, 40(I), 433; Chem. Zent. 1910, 81(II), 641.

78. Fischer, E. Liebigs Ann. Chem. 1877, 190, 67.

79. Dewar, M. J. S. The Electronic Theory of Organic Chemistry; Clarendon: Oxford, 1949; p 95.

80. Angyal, S. J.; Warburton, W. K. Aust. J. Sci. Res., Ser. A, 1951, 4, 93.

81. Brown, H. C.; Pilipovich, D. J. Am. Chem. Soc. 1960, 82, 4700.

82. Spasov, A.; Golovinskii, E. Zh. Obshch. Khim. 1962, 32, 3394; Chem. Abstr. 1963, 58, $11324 \mathrm{e}$.

83. Neilson, D. G. In Some Newer Physical Methods in Structural Chemistry; Bonnett, R.; Davis, J. G. Eds.; United Trade Press: London, 1967; p 186.

84. Neilson, D. G.; Roger, R.; Heatle, J. W. M.; Newlands, L. R. Chem. Rev. 1970, 70, 151.

85. Pellizzarri G.; Gaiter, A. Gazz. Chim. Ital. 1914, 44, 72.

86. Haldeman, R. G.; Morin, L. T.; Matsuda, K. (American Cyanamid Co.), U. S. Patent 1963, 3,075,013; Chem. Abstr. 1963, 58, 11276 b.

87. Pinner, A.; Caro, N. Ber. Dtsch. Chem. Ges. 1895, $28,465$.

88. Jerchel, D.; Fischer, H. Liebigs Ann. Chem. 1951, 574, 85.

89. Kunimine, N.; Itano, K. J. Pharm. Soc. Jpn., 1954, 74, 726; Chem. Abstr., 1955, 49, 11627c.

90. Nineham, A. W. Chem. Rev. 1955, 55, 355.

91. Sharp, D. B.; Hamilton, C. S. J. Am. Chem. Soc. 1946, 68, 588.

92. Ulrich, H. The Chemistry of Imidoyl Halides; Plenum: New York, N. Y., 1968.

93. Jaeken, J.; Jansseune, R. L. (Gevaert Photo-Producten, N. V.) U. S. Patent 3,245,788, 1966; Chem. Abstr. 1966, 65, 844d.

94. Bredereck, H.; Gompper, R.; von Schuh, H. G.; Theilig, G. Angew. Chem. 1959, 71, 753.

95. Bredereck, H.; Gompper, R.; Klemm, K.; Rempfer, H. Chem. Ber. 1959, 92, 837.

96. Schmidt, P.; Druey, J. Helv. Chim. Acta 1955, 38, 1560.

97. Rätz, R.; Schroeder, H. J. Org. Chem. 1958, 23, 1931.

98. Hallmann, F. Ber. Dtsch. Chem. Ges. 1876, 9, 389.

99. Bamberger, E.; Padova, R.; Ormerod, E. Ann. 1925, 446, 269.

100.Jerchel, D.; Kuhn, R. Liebigs Ann. Chem. 1950, 568, 185.

101.Jerked, D.; Woticky, W Liebigs Ann. Chem. 1957, 605, 191.

102.Dickoré, K. Liebigs Ann. Chem. 1964, 671, 135.

103. Brown, H. C.; Cheng, M. T. J. Org. Chem. 1962, 27, 3240.

104. Stevens, C. L.; Freeman, R. C.; Noll, K. J. Org. Chem. 1965, $30,718$.

105. Chattaway, F. D.; Parkes, G. D. J. Chem. Soc. 1926, 113.

106. Thiele, J.; Bihan, R. Liebigs Ann. Chem. 1898, 302, 299.

107.Bladin, J. A. Ber. Dtsch. Chem. Ges. 1889, 22, 796; ibid. 1892, 25, 183.

108.Paul, H.; Chatterjee, S.; Hilgetag, G. Chem. Ber. 1968, 101, 3696.

109.Dornow, A.; Fischer, K. Chem. Ber. 1966, 99, 72. 
110.Weidinger, H.; Kranz, J. Chem. Ber. 1963, 96, 1049.

111.(a)Gibson, M. S.; Murray, A. W. J. Chem. Soc., 1965, 880. (b) Smith, R. F.; Briggs, P. C. Chem. Commun. 1965, 120. (c) Wawzonek, S.; Gueldner, R. C. J. Org. Chem. 1965, 30, 3031. For a review see: McKillip, W. J.; Sedor, E. A.; Culbertson, B. M.; Wawzonek, S. Chem. Rev. 1973, 73, 755.

112.Aly, A. A.; Gomaa, M. A.-M.; Nour-El-Din, A. M.; Fahmi, M. S. Z. Naturforsch. 2006, $61 B, 1239$.

113.Jiang, B.; Gu, X. -H. Bioorg. Med. Chem. 2000, 8, 363.

114.Garg, N. K.; Sarpong, R.; Stoltz, B. M. J. Am. Chem. Soc. 2002, 124, 13179.

115.Smith, R. F.; Johnson, D. S.; Abgott R. A.; Madden, M. J. J. Org. Chem. 1973, 38, 1344.

116.Li, J.-H.; Snyder, J. K. J. Org. Chem. 1993, 58, 516.

117.Faul, M. M.; Winneroski, L. L.; Krumrich, C. A. J. Org. Chem. 1999, 64, 2465; ibid. 1998, $63,6053$.

118. Taylor, E. C.; McKillop, A. Adv. Org. Chem. 1970, 7, 1.

119. Taylor, E. C.; Loeffler, P. K. J. Am. Chem. Soc. 1960, 82, 3147.

120.Bhat, G. A.; Montero, J. L. G.; Panzica, R. P.; Wotring, L. L.; Towsend, L. B. J. Med. Chem. 1981, 24, 1165.

121. Anderson, J. D.; Cottam, H. B.; Larson, S. B.; Nord, L. D.; Revankar, G. R.; Robins, R. K. J. Heterocycl. Chem. 1990, 27, 439.

122.Zacharie, B.; Connolly, T. P.; Rej, R.; Attardo, G.; Penney, C. L. Tetrahedron 1996, 52, 2271.

123.Katritzky, A. R.; Nie, P.-L.; Dondoni, A.; Tassi, D. J. Chem. Soc., Perkin Trans. 1 1979, 1961.

124. Naqui, S.; Srinivasan, V. R. J. Sci. Ind. Res. 1962, $21 B, 195$.

125. Nath, T. G. S.; Husain, S.; Srinivasan, V. R. Indian J. Chem. 1977, 15B, 341.

126. Gehlen, H.; Simon, B. Arch. Pharm. 1970, 303, 511.

127.Davidson, J. S.; Dhami, S. S. Chem. Ind. (London) 1978, 92.

128.Sasaki, H.; Sakata, H.; Iwanami, Y. Nippon Kagaku Zasshi 1964, 85, 704.; Chem. Abstr. 1965, 62, 14678g.

129.Spasov, A.; Golovinskii, E. Zh. Obshch. Khim. 1962, 32, 3394; Chem. Abstr. 1963, 58, $11324 \mathrm{e}$.

130.Aly, A. A.; Gomaa, A.-M. M.; Nour-El-Din, A. M.; Fahmy, M. S. ARKIVOC 2007, (xvi), 41.

131.Aly, A. A.; Nour-El-Din, A. M.; Gomaa, M. A.-M.; Fahmi, M. S. Z. Naturforsch. 2008, $63 B, 223$.

132.Aly, A. A.; Nour-El-Din, A. M. J. Chem. Res. 2007, 665.

133.(a) Lee, K.; Hwang, S. Y.; Hong, S. W.; Hong, C. Y.; Lee, C. -S.; Shin, Y.; Kim, S.; Yun, M.; Yoo, Y. J.; Kang, M.; Oh, Y. S. Bioorg. Med. Chem. 1998, 6, 869. (b) Lee, K.; Jung, W. H.; Park, C. W.; Park, H. D.; Lee, S. H.; Kwon, O. H. Bioorg. Med. Chem. Lett. 2002, 12, 1017. 
134.(a) Lichtenthaler, F. W.; Mondel, S. Pure Appl. Chem. 1997, 69, 1853. (b) Lichtenthaler, F. W. Ed. Carbohydrates as Organic Raw Materials; VCH: Weinheim, New York, 1991. (c) Cottier, L.; Descotes, G. Trends Heterocycl. Chem. 1991, 2, 233.

135.El Ashry, E. S. H.; El Nemr, A. Synthesis of Naturally Occurring Nitrogen Heterocycles from Carbohydrates, Blackwell: Oxford, 2005.

136.(a) El Ashry, E. S. H.; Awad, L. F. Carbohydr. Res. 1998, 312, 9. (b) El Ashry, E. S. H.; Awad, L. F. Nucleosides, Nucleotides \& Nucleic Acids 2001, 20, 103.

137.(a) El Ashry, E. S. H.; El Kilany, Y. Adv. Heterocycl. Chem. 1997, 67, 391. (b) ibid. 1997, 68, 1. (c) ibid. 1998, 69, 129.

138.El Ashry, E. S. H.; Awad, L. F.; Winkler, M. J. Chem. Soc., Perkin Trans. $12000,829$.

139.E1 Ashry, E. S. H.; Abdul-Ghani, M. M. Nucleosides, Nucleotides \& Nucleic Acids 2004, 23, 567.

140.Bendiak, B.; Salyan, M. E.; Patoja, M. J. Org. Chem. 1995, 60, 8245.

141.Remy, D. C. (E. I. du Pont de Nemours and Co.), U. S. Patent 3,061,590, 1962; Chem. Abstr. 1963, 58, 8057b. U.S. Patent 3,115,498, 1963; Chem. Abstr. 1964, 60, 5512g.

142.Gladding, B. K.; Remy, D. C. (E. I. du Pont de Nemours and Co.) U. S. Patent 3,102,889 1963; Chem. Abstr. 1964, 60, 4155f.

143.Hackmann, J. T. (Shell Development Co.), U. S. Patent 2,758,050, 1956; Chem. Abstr. 1956, $50,17306 \mathrm{~d}$.

144. Morin, L. T.; Matsuda, K. (American Cyanamid Co.), U. S. Patent 3,033,893, 1962; Chem. Abstr. 1962, 57, 14948d.

145.Klingsberg, E. (American Cyanamid Co.), U. S. Patent 2,884,424, 1959; Chem. Abstr. 1960, $54,2763 \mathrm{a}$.

146.Joyce, A. W. (American Cyanamid Co.), U. S. Patent 2,967,867, 1961; Chem. Abstr. 1961, $55,8873 \mathrm{~d}$.

147. Gevaert-Agfa N. V. Netherlands Application 6,509,590, 1960; Chem. Abstr. 1966, 64, 18776h; ibid. 1967, 66, 90161t.

148.Kurzer, F.; Godfrey, L. E. A. Angew. Chem., Int. Ed. Engl. 1963, 2, 459.

149.Grundmann, C. J.; Kreutzberger, A. (Olin Mathieson Chemical Corp.) U. S. Patent 2,763,661, 1956; Chem. Abstr. 1957, 51, 3669b.

150.Bertrand, J.; Dobritz, C.; Beerens, H. Bull. Soc. Pharm. Lille, 1956, 39; Chem. Abstr. 1957, $51,1168 \mathrm{~b}$.

151.Libermann, D.; Rist, N.; Grumbach, F. Bull. Soc. Chim. Biol. 1946, 38, 321.

152.Sensi, P.; Timbal, M. T.; Greco, A. M. Antibiot. Chemother. 1962, 12, 488; Chem. Abstr. 1963, 58, 1304d.

153.Greco, A. M.; Ballotta, R.; Sensi, P. Farmaco (Pavia), Ed. Sd, 1961, 16, 755; Chem. Abstr. 1962, 57, $12474 \mathrm{~h}$.

154. Taylor, E. C.; Weinstock, J. British Patent 951,653, 1964; Chem. Abstr. 1964, 61, 4378b.

155. Weinstock, J. (Smith, Kline and French Laboratories), U. S. Patent 3,111,520 (1963); Chem. Abstr. 1964, 60, 5523h. 


\section{Biographical Sketches}

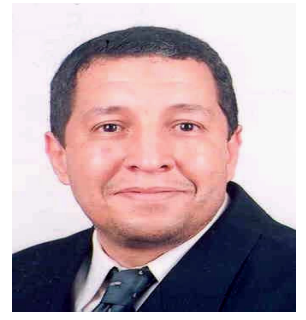

Ashraf Abd El-Moneim Aly Shehata was born on 14 May 1963 in El-Minia, Egypt. He is a Professor of Organic Chemistry in Chemistry Department, Faculty of Science, Organic Division, El-Minia University, 61519-El-Minia, Egypt; tel: +20100042284; e-mail: ashrafaly63@yahoo.com. He was awarded with a channel system program to complete his $\mathrm{PhD}$ program under the supervision of Prof Dr Henning Hopf, in the field of cyclophane chemistry for two years at TU-Brauschweig, Germany. Awarded with a scientific grant to be a scientific visitor to TU-Braunschweig, Germany from 28 November 1997 until 31 January 1999. Awarded as a visiting Professor in Sultan of Oman. Awarded with "The State's Encouragement National Prize in Organic Chemistry (2004) from the Academy of Science and Technology, Cairo, Egypt". Awarded with DAAD scholarship for two months from 12 August 2005 until 12 October 2005 with Prof Dr Henning Hopf. Prof. Aly has been selected on the boards of referees in the following journals: Journal of Organic Chemistry, Journals of Royal Society of Chemistry (RSC) and Arkivoc. Acknowledged by Shoman foundation for his research program and his list of publications. He has published 64 papers including 2 review articles. He has a joint research with Prof Dr Alan B. Brown, Chemistry Department, University Blvd, Melbourne, Florida, U.S.A. and has a prospective cooperation with Prof. Dr. Shinmyozu teruo, Department of Applied Molecular Chemistry, Institute for Materials Chemistry and Engineering, Japan. The research group of Professor Ashraf A Aly is working for a long time on the chemistry of [2.2]paracyclophane and is interested in study of synthetic approaches to new cyclophanes containing heterocyclic rings. Moreover, his research activity deals with synthesis of heterocycles which may have prospective biological and/or pharmaceutical activities.

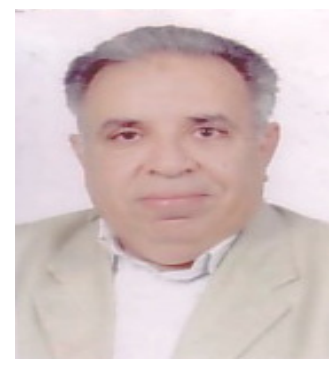

Ahmed Moukhtar Nour-El-Din was born in El Minia, A.R. Egypt, in 1946. He obtained his B.Sc. degree from Assuit University in 1968, and his M.Sc. degree from the same university in 
1975. He received his Ph.D. degree from Kaiserslautern University, Germany in 1979, under the supervision of Professor D. Döpp. He became Lecture in the department of chemistry of the Assuit University in 1979, and Associated Professor in the Department of Chemistry of the ElMinia University in 1983. He was visiting professor at the university of Anaba, Anaba, Algeria from 1986 to 1989, and University of Kuwait from 1996 to 1997. He was appointed Head of Chemistry Department in 1990 and 2004. He received DAAD fellowships in 1983, 1986 and 1997. His research interests cover chemical study of the reactivity of electron-rich compounds towards electron-poor compounds, and also charge- transfer complexes. 